\title{
Progress and Perspective of Antiviral Protective Material
}

\author{
Jialiang Zhou ${ }^{1} \cdot$ Zexu Hu$^{1} \cdot$ Fatemeh Zabihi ${ }^{1} \cdot$ Zhigang Chen $^{1} \cdot$ Meifang Zhu ${ }^{1}$
}

Received: 21 April 2020 / Accepted: 1 May 2020 / Published online: 23 June 2020

(c) Donghua University, Shanghai, China 2020

\begin{abstract}
Public health events caused by viruses pose a significant risk to humans worldwide. From December 2019 till now, the rampant novel 2019 coronavirus (SAR-CoV-2) has hugely impacted China and over world. Regarding a commendable means of protection, mask technology is relatively mature, though most of the masks cannot effectively resist the viral infections. The key material of the mask is a non-woven material, which makes the barrier of virus through filtration. Due to the lack of the ability to kill the viruses, masks are prone to cross-infection and become an additional source of infection after being discarded. If the filteration and antiviral effects can be simultaneously integrated into the mask, it will be more effcient, work for a longer time and create less difficulty in post-treatment. This mini-review presents the advances in antiviral materials, different mechanisms of their activity, and their potential applications in personal protective fabrics. Furthermore, the article addresses the future challenges and directions of mask technology.
\end{abstract}

Keywords Protective material $\cdot$ Antiviral $\cdot$ Fiber $\cdot$ Nanotechnology

\section{Introduction}

Emerging infectious diseases caused by viruses have constituted the forefront of global health concerns [1]. At present, China and the world are experiencing the outbreak of atypical pneumonia caused by the zoonotic 2019 novel coronavirus, SAR-CoV-2 (2019-nCoV). As of Feb 16, 2020, there have been more than 60,000 cases of this 2019 coronavirus disease (COVID-19) confirmed in mainland China, including more than 1000 deaths [2]. The SARS-CoV-2 viruses are generally spherical with some pleomorphism, the diameter varies from $60-140 \mathrm{~nm}$, and the surface covered by distinctive spikes, with an average lenght of 9-12 nm [3, 4]. In perspective, two other novel coronaviruses (CoVs) have caused two large-scale pandemics in the last two decades, namely, severe acute respiratory syndrome coronavirus (SARS-CoV; in 2002) and Middle East respiratory syndrome coronavirus (MERS-CoV; in 2012) which both have been seen in many countries [4].

Meifang Zhu

zhumf@dhu.edu.cn

1 State Key Laboratory for Modification of Chemical Fibers and Polymer Materials, Shanghai Belt and Road Joint Laboratory of Advanced Fiber and Low-Dimension Materials, College of Materials Science and Engineering, Donghua University, Shanghai 201620, China
COVID-19 (like many other diseases) can be transmitted from an infected person through exhalation or emittion of body fluids or aerosol particles containing the virus, which then attach to the surfaces and subsequently touched by receiver person. Aerosolized pathogens are the leading agent of the respiratory infections and their body-to-body transmissions cycle. The parameters behind respiratory protection and airborne transmission intertwine in a complex system that can be broken down into four bidirectional components: (1) release, (2) infection, (3) filtration, and (4) protection (Fig. 1). Aerosols play a prominent role in spreading of viruses in the air. Aerosol particles with different sizes can infect the host's respiratory tract through different mechanisms (da $<10 \mu \mathrm{m}$, alveolar regions; $10<\mathrm{da}<100 \mu \mathrm{m}$, upper respiratory tract) [5]. Therefore, additional studies are urgently needed to curb the spread of viral infections. The use of respiratory protection devices has been shown to be an effective non-pharmaceutical intervention to reduce the spread of respiratory viruses, primarily when used by individuals in enclosed spaces, in close contact with a person revealing pandemic-like symptoms.

Herein, we describe the ways and mechanisms of virus transmission and summarize the problems, faced by respiratory protection devices technology. Meanwhile, we briefly review the recent research progresses in antiviral nanomaterials, including their main physicochemical characteristics, 


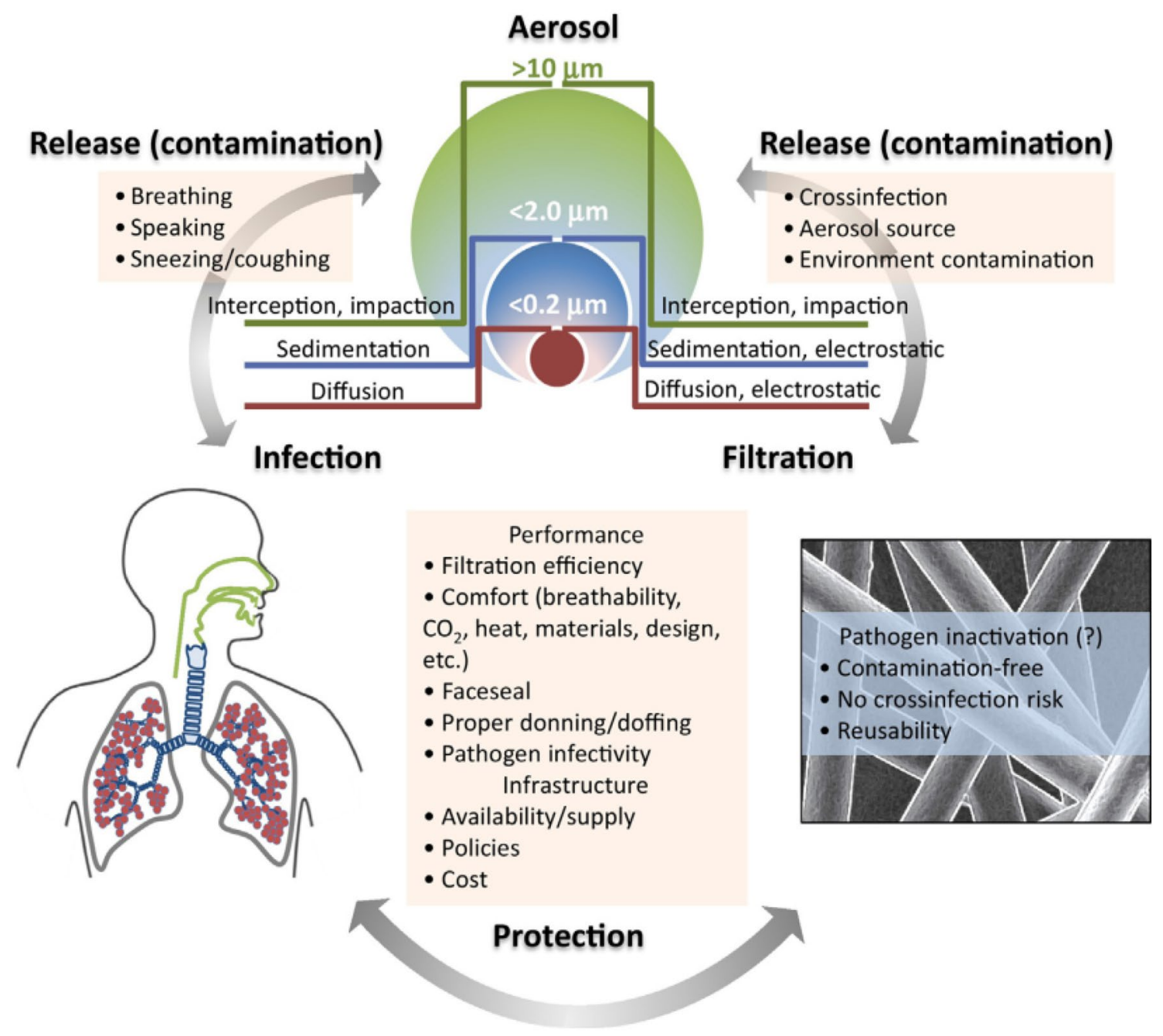

Fig. 1 Respiratory protection and airborne transmission intertwine system. Panel in this figure is reproduced with permission from Ref. [5]. Copyright 2017 Elsevier

the various mechanisms of antiviral function of these materials, and the effect of the combination of antiviral nanomaterials and textiles on perotection performance of related face masks. Lastly, the challenges and future perspectives of the application of nanotechnology in antiviral textiles are discussed.

\section{Current Protect Tools Based on Non-woven Fabrics}

Current personal protective tools (medical masks and protective clothing) are used to effectively filter the particles in the air and block the droplets, blood, body fluids, secretions, and so on. The objects of protection are generally infectious microorganisms, bacterial particles in the air, and aerogels containing pathogens [6]. The medical protective masks are typically made of multiple nonwoven layers, including functional wet-resistant spunbonded nonwoven layer, meltblown nowoven layer, and skin-friendly spunbonded nonwoven layer. The primarily filtering mechanisms of the medical protective masks are interception, inertial impact, and electrostatic deposition. The filtration efficiency of ordinary filtering materials can only reach up to $85 \%$ [7]. In order to ensure the filtration performance of surgical masks, electret treatment is essential. After the electret treatment, the filtering material will have a positive charge, through which the filtration efficiency can be increased to over $95 \%$. Since the trapped objects (such as bacteria, viruses and aerosols) are negatively charged, they will be blocked or trapped by created electrical field when they are carried by air flow through the positively charged fibers [7, 8] (Fig. 2).

In most of the regular protective masks (such as N95 masks), the protection performance is mainly determined by the filtration characteristics of the filled non-woven layer (including filtration thickness, packing density, fiber 


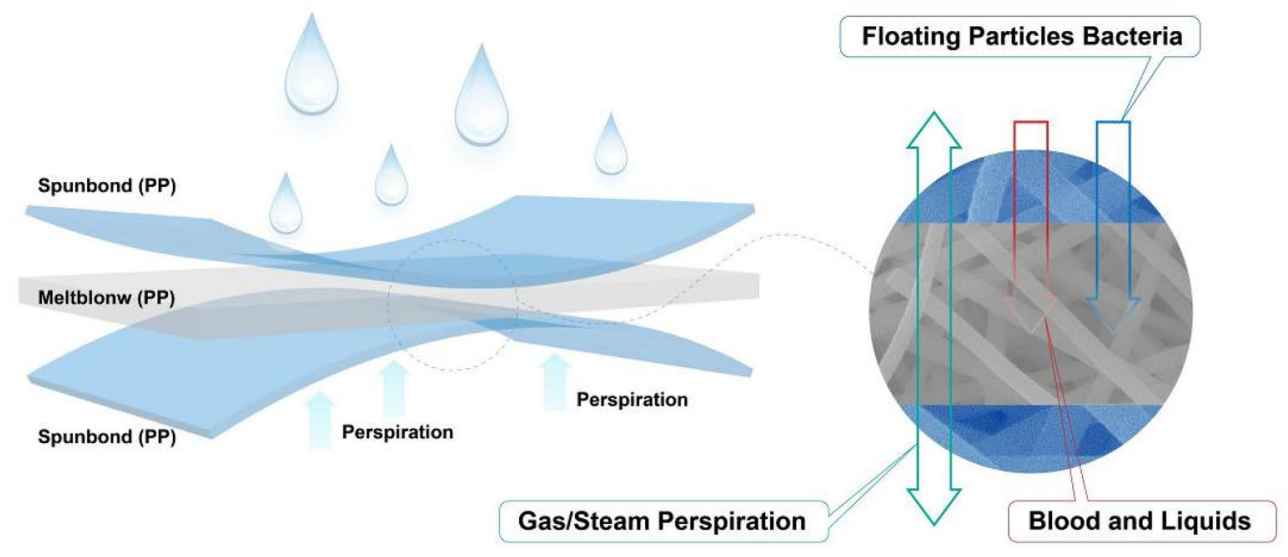

Fig. 2 Schematic of structure and protection mechanism of current ordinary face masks

diameter, fiber charge) and particle characteristics (diameter, density, and velocity) [9]. If the surface of the protective mask is contaminated with droplets during the practical applications, the virus could penetrate into the protective layer along with the droplets. Besides, the hands of medical staff or users could get contaminated when mask is removed. Generally, the effectiveness of these masks depends on their proper usage and handling. Improper usage and touch could dramatically increase the risk of pathogens transmission [10], as is the case with the current COVID-19 epidemic. Furthermore, it is necessary to functionalize the filtration systems by addition of nanomaterials, and producing the reusable virus inactivating devices. Such a functional enhancement mitigates the risk of being infected by direct or secondary vectors [11].

Current advancements in nanotechnology provide a platform for minimizing the risk of transmission of infectious agents from contaminated protective equipment such as masks. A possible pathway to this perspective is to equip the personal protective devices with antiviral elements. Such an essential upgrading can be obtained by embedding the antiviral nanomaterials in the fibers or non-woven fabrics which are typically used as face protective materials. For this purpose, both inorganic and organic materials and composites can be used as the functional elements. Nevertheless, different materials with different physical and chemical natures, stabilities and degrees of anti-mirobial functions should require different applications and manufacturing processes.

\section{Metal-Based Nanomaterials as Antiviral Materials}

Metal-based nanoparticles have unique physicochemical properties due to their small size and high specific surface area, which enable them to interact with viruses and other micro-organisms. A variety of metal and metal oxide nanoparticles (such as silver, copper, titanium, gold, and zinc) have been introduced as antiviral agents [12]. Table 1 summarizes and compares the typical metal-based nanoparticles antiviral materials. Infection of the host cells by viruses mainly occurs via four mechanisms: attachment, penetration, replication, and budding. On the other hand, antiviral function of metal-based nanoparticles contains three interacting stages, (1) Linking of connecting to the virus and inhibiting the virus attachment penetration into the cell; (2) generation

Table 1 Comparison of the typical metal-based nanoparticles antiviral materials

\begin{tabular}{|c|c|c|c|c|}
\hline Types & Preparation & Size $(\mathrm{nm})$ & Performance & References \\
\hline Ag NPs & Electrochemical & 7.1 & Infected cells cultured in $100 \mathrm{ppm} \mathrm{Ag} \mathrm{NPs} \mathrm{for} 48 \mathrm{~h}$, the cell survival rate reach $98 \%$ & [14] \\
\hline Ag@OTV & Surface modifier & 3 & The cell survival rate remains $90 \%$ & {$[18]$} \\
\hline $\mathrm{Ag}_{2} \mathrm{~S}$ NPs & Chemical reduction & $<5$ & Inhibited PEDV more than $99 \%$ & {$[22]$} \\
\hline Au NPs & Chemical reduction & 10 & Reduce viral infections (a reduction of $92 \%$ after $6 \mathrm{~h}$ interaction) & {$[31]$} \\
\hline $\mathrm{CuO}$ NPs & Surface modifier & $<100$ & Improve five orders of magnitude in virus-killing than the control N95 & [42] \\
\hline $\mathrm{Cu}_{2} \mathrm{O} \mathrm{NPs}$ & Chemical reduction & 50 & Reduce viral infections (a reduction of $90 \%$ at concentration of $4 \mu \mathrm{g} / \mathrm{mL}$ ) & {$[43]$} \\
\hline $\mathrm{TiO}_{2}$ & Sonochemical & 8 & Excellent antiviral performance against NDV at the concentration of $6.25 \mu \mathrm{g} / \mathrm{mL}$ & {$[51]$} \\
\hline
\end{tabular}




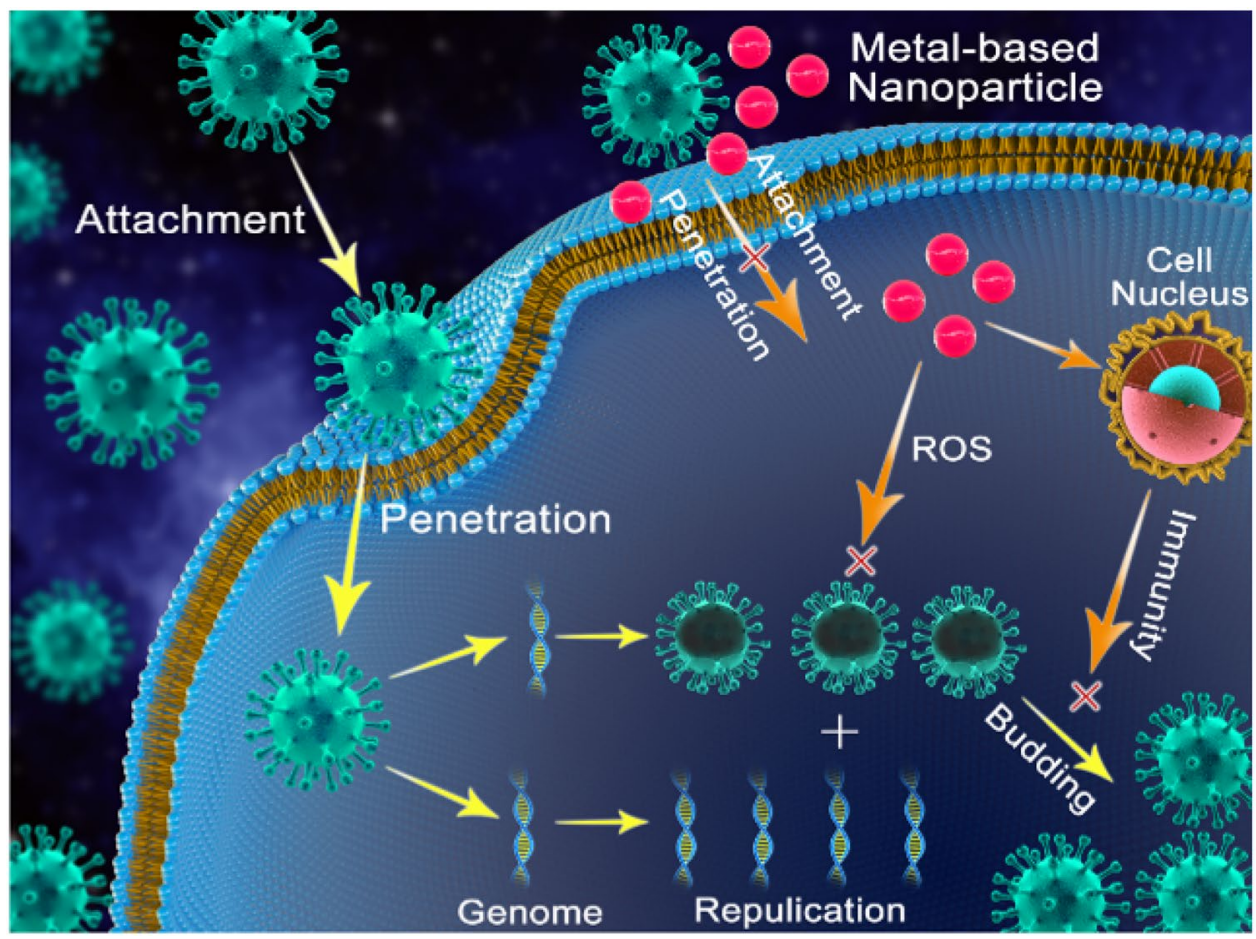

Fig. 3 Schematic presentation of antiviral mechanism of metal-based nanoparticles

of highly active oxygen and other ions and radicals which adhere to the wall (spkies or membrane) and destroy the structure and function of viral proteins and nucleic acids; (3) simulating the nucleus to increase the immune response of the host cell, and inhibiting the budding and spreading of the virus (Fig. 3).

\section{Silver-Based Antiviral Nanoparticles}

Silver and it's derivatives are known a classic anti-microbial compounds, and are still in high-demand for their impressive anti-pathogen performance. Silver nanoparticles (Ag NPs) can simply interact with the outer layers of the virus and prevent their attachement on and penetration into the host cells. The average particle size of $\mathrm{Ag}$ NPs is an important factor that affects its antiviral ability. For example, Krzyzowska et al. [13] report the synthesis of Ag NPs with an average particle size of $33 \mathrm{~nm}$, prepared by chemical reduction method, using tannic acid as surface ligands. This Ag NPs couls effectively control the herpes simplex virus type 2 (HSV-2) infection in mice by inhibiting the adhesion of the virus to host cells. Interestingly, this process produced no toxic and pro-inflammatory incidences (Fig. 4a). To obtain Ag NPs with smaller particle sizes, Huy et al. [14] suggested a simple electrochemical method, and obtained a Ag NP sample with an average size of $7.1 \mathrm{~nm}$. In a 48-hours cultural test with $100 \mathrm{ppm}$ Ag NPs, the cell survival rate was determined to be as high as $98 \%$, whereas the cell viability was only $2 \%$ in control samples (without Ag NPs). The antiviral function is related to this fact that the Ag NPs can easily contact with polioviruses $(25-30 \mathrm{~nm})$, and destroy their proteins molecules, so that prevent them to bind with the host cells. Addition of surfactants to the synthesis method can control the average size of Ag nanoparticles. Many types of surfactants (such as PVP [15], citric acid [16] and plant polyphenol [17]) have been suggested for this application, as their influence on average particles size could substantially improve the anti-infection function of Ag NPs.

To improve the antiviral activity, some therapeutic agents can be used as the surface ligands for Ag NPs. For example, Oseltamivir (OTV) is a therapeutic agent for antiviral applications. Zhu et al. [18] used OTV as the surface modifier and synthesized Ag@OTV NPs with average size of $3 \mathrm{~nm}$. When Ag@OTV solution was used to culture the cells infected with influenza virus (H1N1), the cell survival rate remained as high as $90 \%$, which is obviously highed than that of bare AG MPs (65\%). This enhancement resulted from the synergistic anti-infection effects of Ag NPs and OTV ligands. Ag@OTV could effectively inhibit H1N1 influenza, creating virus-induced apoptosis of host cells. This could mainly occur through ROS-mediated p53 and AKT signaling pathways (Fig. 4b). Similarly, other therapeutic agents (such as amantadine [19], zanamivir [20], and aminoadamantane [21]) have also been coupled with Ag NPs, and the resulting NPs exhibited boosted antiviral activity. 

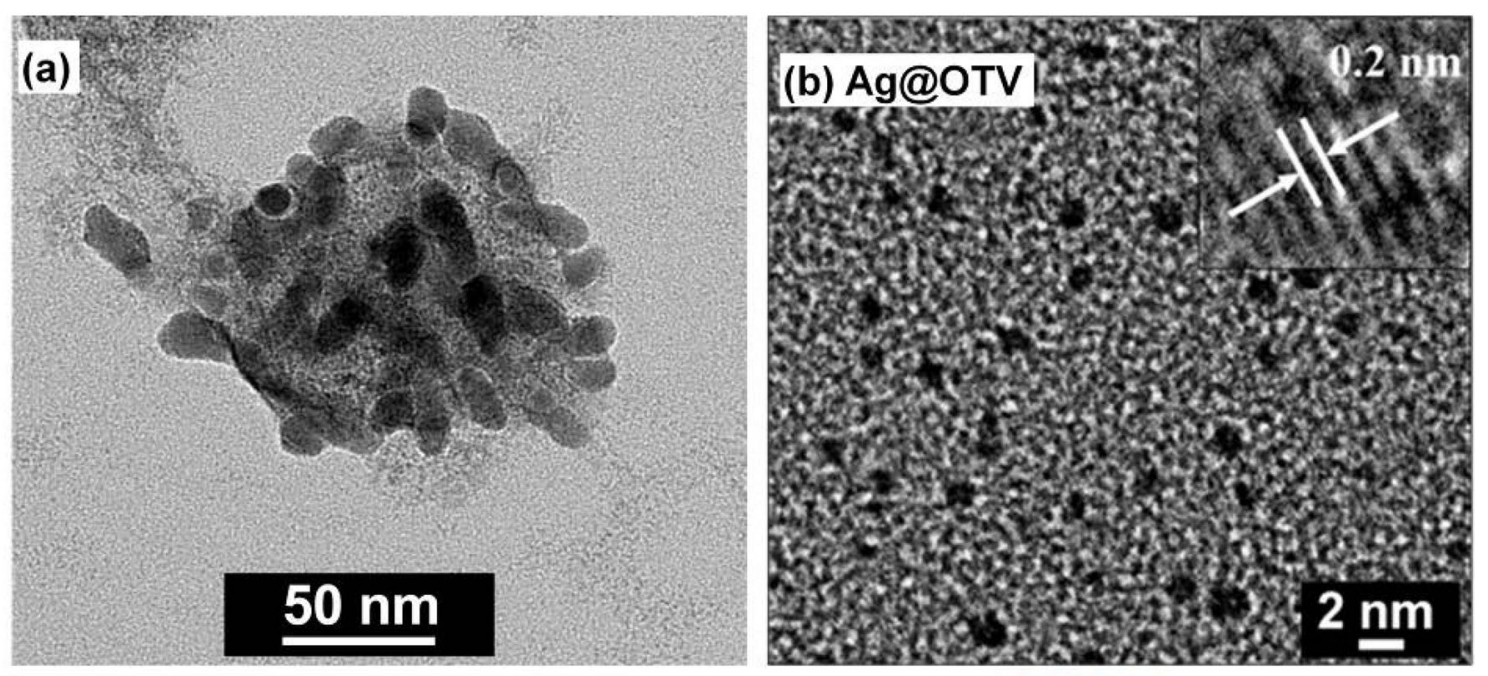

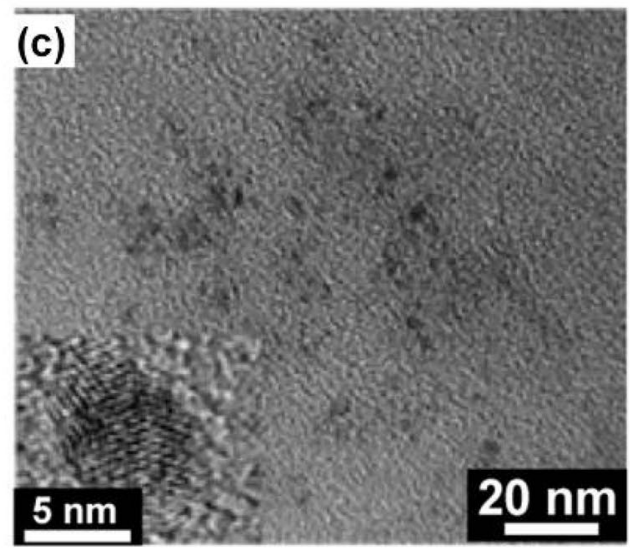

Fig. 4 Silver-based antiviral nanoparticles. a HSV-2 covered with silver nanoparticles (Ag NPs). a Reproduced with permission from Ref. [13]. Copyright 2018 MDPI. b SEM image of of Ag@OTV particles. Lattice orientation obtained from transmission electron microscopy (TEM), is depicted on inset. b Reproduced with permission from

Beyond silver nanoparticles, other silver compounds are also considered as effective antiviral materials. Han et al. [22] prepared $\mathrm{Ag}_{2} \mathrm{~S}$ nanoparticles $\left(\mathrm{Ag}_{2} \mathrm{~S} \mathrm{NCs}\right)$ with average size of less than $5 \mathrm{~nm}$ by using glutathione as a capping reagent (Fig. 4c). $\mathrm{Ag}_{2} \mathrm{~S}$ NCs inhibited the porcine epidemic diarrhea virus (PEDV, a positive-strand RNA virus) more than $99 \%$, and demonestrated an acceptable biological safety. In addition, $\mathrm{Ag}_{2} \mathrm{~S}$ NCs can affect on some other types of RNA viruses (PRRSV), as well. The antiviral activity of $\mathrm{Ag}_{2} \mathrm{~S}$ NCs is mainly ruled out by inhibiting RNA synthesis and viral budding. It was also argude that, the activation of ISG proteins and pro-inflammatory cytokines might be an important factor in this case (Fig. 4d). Similarly, other silver compounds (such as silver bis(citrato)germinate [23] $\mathrm{AgNO}_{3}$ [24] and silver acesulfame [25]) have been known as the excellent anti-virus substances.

The above mentioned studies have proved that silver and its derivative compounds are of strong virus killers. (d)

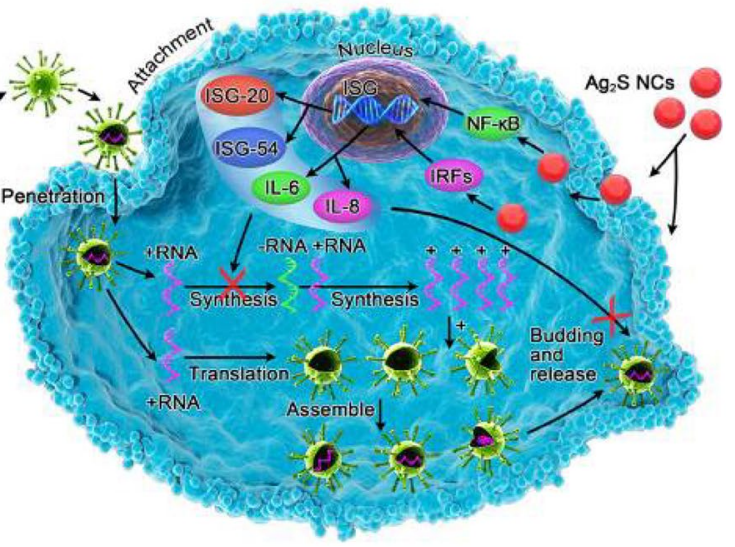

Ref. [18]; Copyright 2016 American Chemical Society. c TEM image of $\mathrm{Ag}_{2} \mathrm{~S}$ NCs. Lattice orientation obtained from TEM, is depicted on inset. d Mechanisms of the antiviral activity of $\mathrm{Ag}_{2} \mathrm{~S}$ NCs. c, d Reproduced with permission from Ref. [22]; Copyright 2018 American Chemical Society

However, there is still a serious challange in combination of silver (or silver-derivative) NPs with fibers, when they are going to be applied in personal protection equipment. Surface coating is a facile technology for this application. Wang et al. [26] used surface coating for deposition of Ag NP on silk at the supporting materials. Ag NPs induced a powerful pathogen killing ability, which could be visually indicated by color changes, due to the plasmon resonance effect of Ag NPs. When Ag NPs-decorated silk fibers were used to contact pathogens, more than $99 \%$ of E. coli specimen was destroyed. This process can be completed in a short course of time, at room temperature, and is associated with low energy consumption and environmental protection. Other fiber materials (such as polyester [27], cotton [28], and chitosan [29]) can also prominently contribute to the antibacterial activities when are coated by Ag NPs. However, there are, so far, few results and evidences on the antiviral 
properties of Ag NPs-decorated fiber, which atill need to be addressed in wider field.

\section{Gold-Based Antiviral Nanoparticles}

Gold nanoparticles (Au NPs) possess excellent biocompatibility, stability, and ability to bind with biological ligands (bioconjugation), which has great relevance for applications in the field of antiviral materials [30]. The mechanism of viral inhibition by Au NPs has been realized to be based on blocking the viral particles to be binded to the cell, thereby inhibiting virus attachment/entry and controlling the cellto-cell spread of the virus. For instance, Laura et al. [31] prepared $\mathrm{Au}$ NPs with particle the average size of $10 \mathrm{~nm}$ via chemical reduction method using the plant extracts as the reducing agent (Fig. 5a). This Au NPs could significantly reduce the viral infections (a reduction of $92 \%$ after $6 \mathrm{~h}$ interaction). The virucide effect of Au NPs was perhaps due to the interaction of the Au NPs with the viral receptors, inhibiting the virus attachment to the host cells and avoiding viral infection (Fig. 5b). In order to further explore the effect of the average size of Au NPs on antiviral efficacy was considered. Haag et al. [32] used sialic acid-terminated glycerol dendrite as ligand, to obtain two different sizes of Au NPs ( $2 \mathrm{~nm}$ and $14 \mathrm{~nm}$ ). The particles average size was shown to be substantially determinant in antiviral ability. When a dispersion of $14 \mathrm{~nm} \mathrm{Au} \mathrm{NPs} \mathrm{was} \mathrm{applied} \mathrm{in} \mathrm{a} \mathrm{culture} \mathrm{medium,}$ containg the cells infected by influenza virus (Fig. $5 \mathrm{c}$ ), the

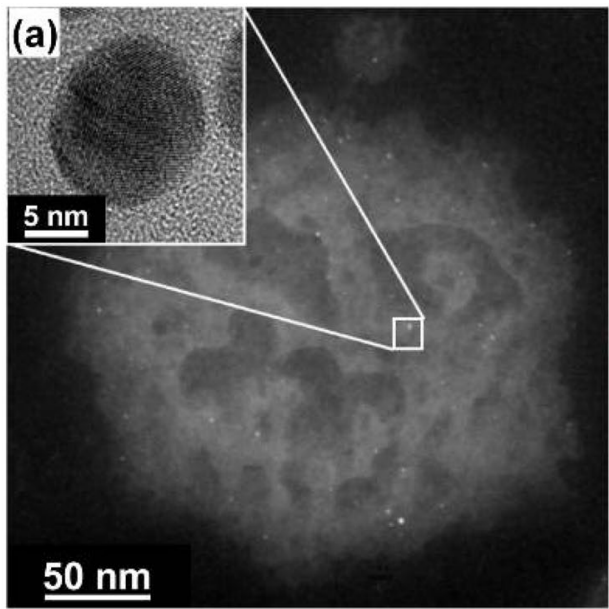

(b)
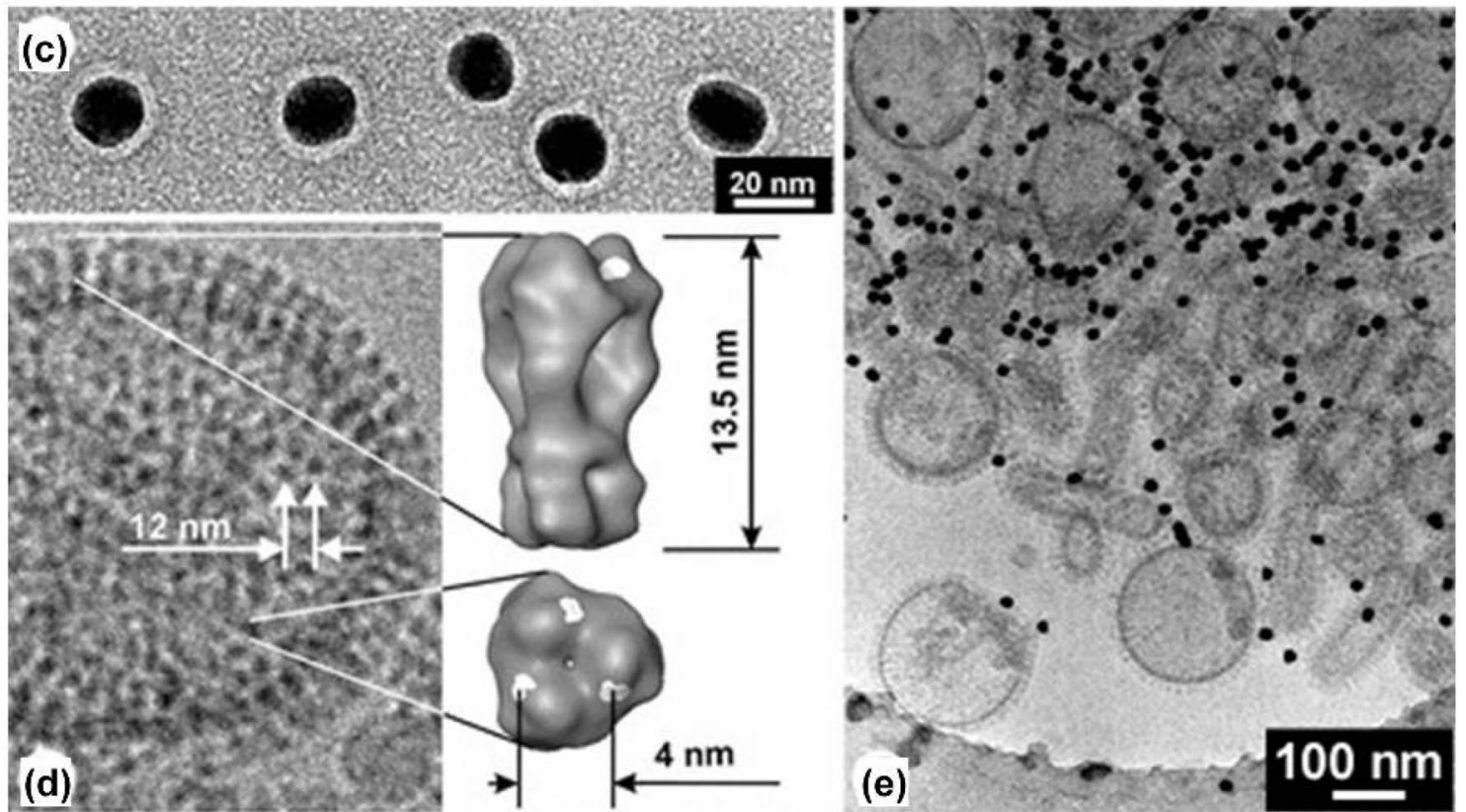

Fig. 5 Gold-based antiviral nanoparticles. a Measles virus exposed to Au NPs. b Schematic representation of the virucidal effect of $\mathrm{Au}$ NPs. a, b Reproduced with permission from Ref. [31]. Copyright 2019 MDPI. c Amphiphiles functionalized Au NPs. d Influenza
AX31 virion showing the individual trimeric fusion protein HA sticking out of the viral membrane. Receptor binding sites. e Au nanoparticles binded to virus. c-e Reproduced with permission from Ref. [32]; Copyright 2010 Wiley 
cell survival rate remains as high as $60 \%$. The same test with $2 \mathrm{~nm} \mathrm{Au}$ NPs could only save 5\% of the cells population. Such a notable difference was attributed to the multivalent effect, which cause the larger Au NPs make a stronger binding forces with the protein molecules on the surface of virus (Fig. 5d, e). As a size controlling factor, various types of surfactants (such as $N$-acetylneuraminic acid [33], peptide [34], and nucleic acid [35]) were tested in synthesis madia, and the issuing Au NPs were compared bsed on their sizedependent antiviral potentials activities.

In order to improve the specificity of Au-based antiviral materials, Huang et al. [36] fabricated a gold nanoparticle BNA conjugated network (DNA-Au NPs). The DNA-Au NPs network exhibited a fascinating antiviral ability against the respiratory syncytial virus (RSV). When the DNA-Au NPs network, RSV virus, and cells were cultured together, the cell survival rate exceeded $90 \%$. This DNA-Au NPs networks formed a protective layer on cell membranes that inhibited viral infections, thereby preventing virus attachment and entry, virus budding and intercellular spreading. Different morphologies of Au NPs have different antiviral properties and mechanisms. Shree et al. [37] presented the antiviral mechanisms of gold nanorods (45 $\mathrm{nm} \times 10 \mathrm{~nm}$ ) against RSV. The survival rate of cells infected with RSV was $82 \%$ in $2.5 \mu \mathrm{g} / \mathrm{mL}$ content of gold nanorods. Gold nanorods inhibited viral infections mainly by inducing a cellular immune response. Cytotoxicity is an important aspect that need to be considered when nanoparticles act on biological systems. However an excessive cytotoxicity will also affect the cell itself. In order to reduce the toxicity of Au NPs and improve its properties, Gabriela et al. [38] constructed micro-nano hybrid materials (Au NPs/LDHs) by assembling the gold nanoparticles $(3.5 \mathrm{~nm})$ on a large scale double hydroxides layer (LDHs, $150 \mathrm{~nm}$ ). Au NPs/LDHs showed excellent antiviral abilities at extremely low concentrations, and the cell survival rate after hepatitis B virus (HBV) infection was over $90 \%$. The gold released from the $\mathrm{Au}$ NPs/LDHs composites interacts directly with the virus particles, and simply trap the viruses in the cell and prevent their transmission from cell to cell. However, the high price of gold nanoparticles limits their scale of use in personal protective equipment.

\section{Copper-Based Antiviral Nanoparticles}

Copper oxide nanoparticles are widely used in antibacterial materials due to their low price, great stability, and broad antibacterial properties $[39,40]$. Few researchers have studied the antiviral properties and mechanisms of copper oxidebased nanoparticles (CuO NPs). This metal oxide and specially it's nanoparticles can destroy the integrity of the virus and the degradation of its genome. Ahmad et al. [41] proved that $\mathrm{CuO}$ NPs have an outstanding anti-HSV-1 virus efficacy, as the cell survival rate reached $83.3 \%$ when $\mathrm{CuO}$ NPs were co-cultured with HSV-1 infected cells, at the highest non-toxic concentration of CuO NPs $(100 \mu \mathrm{g} / \mathrm{mL})$. The copper ions released from $\mathrm{CuO}$ NPs catalize the production of reactive oxygen species (ROS), which can colapse the HSV capsid integrity and degrade the whole genome. In order to explore the application of $\mathrm{CuO}$ NPs in respiratory protective equipment, Gadi et al. [42] reported the preparation of antiviral respiratory protective face mask by impregnation of CuO NPs into an N95 mask. The antiviral respirator was composed of four layers. The outer and inner layers (A, B) have different fiber fineness, and $\mathrm{CuO}$ NPs were evenly distributed on the surface of the fiber, as shown on Fig. 6a, b. The presence of $\mathrm{CuO}$ NPs in the masks acts as the killer of the virions which were remained in the mask without altering its physical barrier properties. With this procedure, the antiviral function of $\mathrm{N} 95$ masks were improved by five orders of magnitude.

Cuprous oxide nanoparticles $\left(\mathrm{Cu}_{2} \mathrm{O}\right.$ NPs $)$ are of other metal-oxides for antiviral purposes. Hang et al. [43] investigated the antiviral efficacy of $\mathrm{Cu}_{2} \mathrm{O}$ NPs against hepatitis $\mathrm{C}$ virus ( $\mathrm{HCV}$ ), in vitro. When the $\mathrm{HCV}$ virus was treated with $\mathrm{Cu}_{2} \mathrm{O}$ NPs at a concentration of $4 \mu \mathrm{g} / \mathrm{mL}$, its infection rate against the cells was reduced by $90 \%$. Antiviral mechanism of $\mathrm{Cu}_{2} \mathrm{O}$ NPs was thought to interfere with the attachment and entry of $\mathrm{HCV}$ virions into host cells. Larger $\mathrm{Cu}_{2} \mathrm{O}$ NPs $(\sim 50 \mathrm{~nm})$ inhibited $\mathrm{HCV}$ viruses $(\sim 30 \mathrm{~nm})$ to be attached to the cells, through the multivalent binding of virions, thereby blocking the entry of the virus into the cell. In order to elucidate the antiviral activity of copper compounds with different valences, Mazurkow et al. [44] synthesized multi-phases $\mathrm{Cu}_{\mathrm{x}} \mathrm{O}_{\mathrm{y}}\left(\mathrm{CuO}\right.$ and $\left.\mathrm{Cu}_{2} \mathrm{O}\right)$ hybrid by calcinating at different atmospheres (Fig. 6c). They concluded that $\mathrm{Cu}_{2} \mathrm{O}$ has a relatively better antiviral ability (Fig. 6d). The difference in antiviral activity between $\mathrm{CuO}$ and $\mathrm{Cu}_{2} \mathrm{O}$ was certified by zeta-potential measurements. $\mathrm{Cu}_{2} \mathrm{O}$ was found to have a higher isoelectric point of 11.0, which makes it more prepared to interact with viruses (Fig. 6e). A similar observation was reported by Kayano [45].

Other $\mathrm{Cu}$-based compounds have also been studied as competitive antiviral materials. Yoshie et al. [46] investigated the antiviral activity of nanosized copper (I) iodide (CuI) particles with average size of $160 \mathrm{~nm}$. CuI particles exhibited a prominent antiviral reaction against influenza A viruses (HIN1), at a concentration of $17 \mu \mathrm{g} / \mathrm{mL}$. Moreover, it was indicated that $\mathrm{CuI}$ generates hydroxyl radicals in aqueous solution, which inactivates the virus by oxidizing the surfacial lipid groups. Other cuprous compounds such as $\mathrm{Cu}_{2} \mathrm{~S}$ and $\mathrm{CuCl}$ have also been verified as potential antiinfections [47]. 

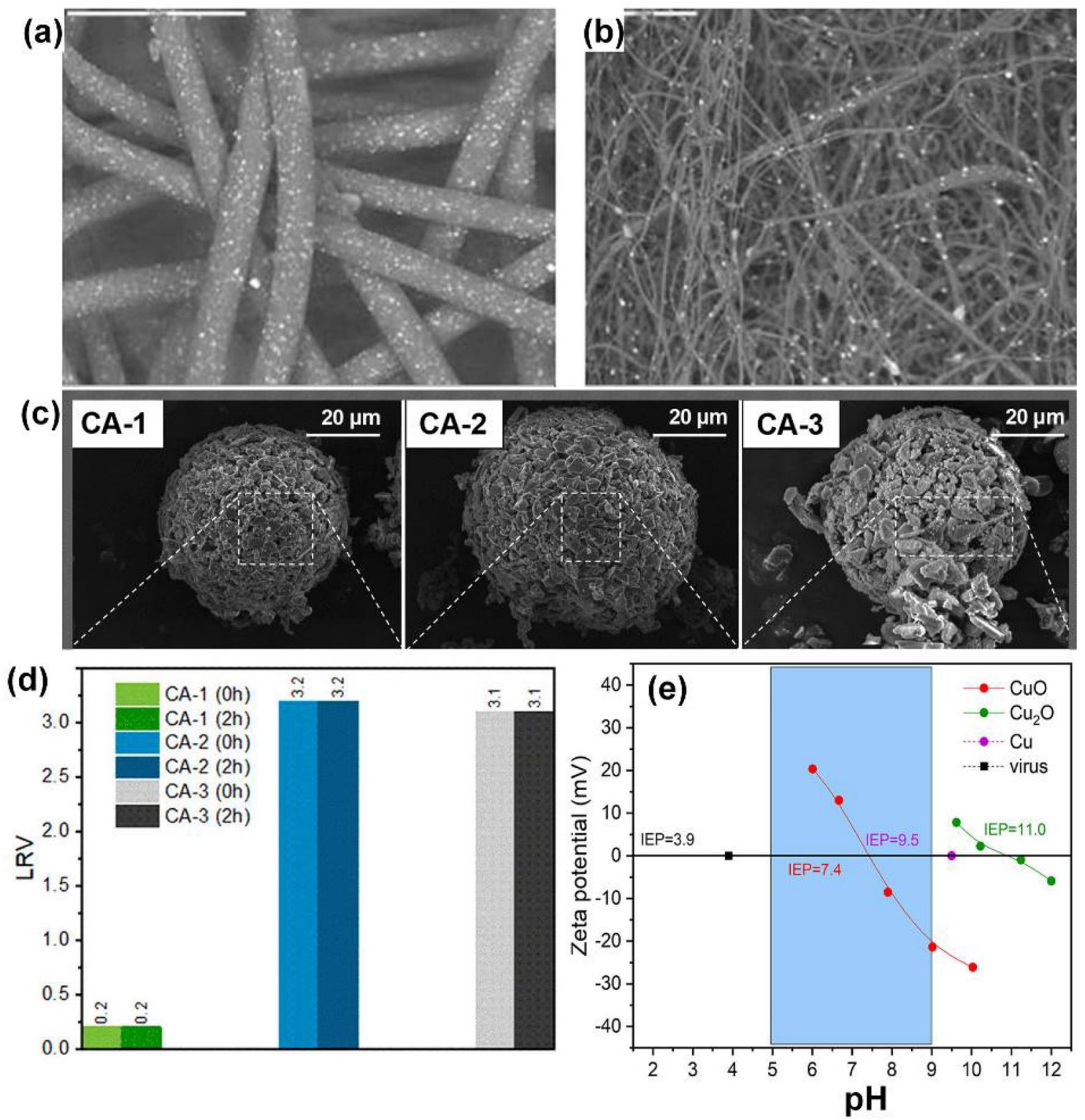

Fig. 6 Copper-based antiviral nanoparticles. a External layer of mask containing $\mathrm{CuO}$ NPs. b Internal layer of mask containing $\mathrm{CuO}$ NPs. a, b Reproduced with permission from Ref. [42]. Copyright 2010 PLoS. c The surface morphology of copper-based hybrids materials.

\section{Other Metal Oxides as Antiviral Nanoparticles}

In addition to the above mentioned materials, the antiviral abilities of the other types of metal nanomaterials have equally been of interest to researchers. Zinc oxide and titanium oxide have been successful in micro-biological assessments, but so far attracted less attentions. Yogendra et al. [48] proved that a negatively charged ZnO NP sample can simply trapped the herpes virus, and inhibit its attachment to the host cells. When $\mathrm{ZnO}$ was co-cultured with viruses and cells, the cell survival rate increased by over $50 \%$. Sun et al. d Antiviral properties of copper-based hybrids materials. e Comparison of zeta potential profile of virus, $\mathrm{CuO}, \mathrm{Cu}_{2} \mathrm{O}$, and $\mathrm{Cu}$. c-e Reproduced with permission from Ref. [44]; Copyright 2020 American Chemical Society

[49] and Seyed et al. [50] separately studied the inhibitory trait of the ZnO NPs on HSV-1. Sara et al. [51] synthesized a $\mathrm{TiO}_{2} \mathrm{NPs}_{\text {sample, }}$ with tetragonal lattice orientaion, and an average particle size of $8 \mathrm{~nm}$, by a simple sonochemical procedure. This $\mathrm{TiO}_{2}$ NPs sample showed an exceptional antiviral performance, versus newcastle virus (NDV), when it's concentration in culture medium was set at $6.25 \mu \mathrm{g} /$ $\mathrm{mL}$. The inhibiting mechanism was defined to be based on destruction of the lipid membrane and blocking the virus attachment. Beyond the mentioned items, there are some other metlas and metal-oxdes anti-viruses, such as tin oxide 
$\left(\mathrm{SnO}_{2}\right)$ [52], gallium [53] and iron oxide [54], which are potential candidates for being embeded into the personal protective fabrics, for daily useage.

\section{Nonmetal Nanomaterials as Antiviral Materials}

\section{Carbon-Based Antiviral Materials}

Carbon atoms can link to each other, in different ways and differenr binding energies, therefore make various allotropes, such as 0D carbon dots (CDs), 1D carbon nanotubes (CNTs), and 2D graphene oxide (GO). Different carbon allotrpes have been examined in term of their anti-microbial effects, which are originating from their unique physical and chemical properties. One of the most important dominating factors is the geometry of the carbon materials, which has shown to be profoundly determinant in their anti-infection perfromance. A brief description of carbon-based nanomaterials with different physicochemical characteristics and antiviral activity is brought in the following section: Han et al. [55] investigated the effect of CDs against viruses by using pseudorabies virus (PRV) and porcine reproductive and respiratory syndrome virus (PRRSV) as the models of DNA and RNA viruses, respectively (Fig. 7a). After CDs treatment, the infection of cells by PRV and PRRSV was reduced to more than $80 \%$, compared with untreated controls (Fig. 7b). They demonstrated that the cells treated with CDs can stop the multiplication of PRV and PRRSV by production of interferon-a (IFN-a) and IFN-stimulating genes (ISGs). The surface properties of CDs affect its safety and biocompatibility. In this context, Huang et al. [56] prepared a core-shell CDs sample, by dry heat treatment of curcumin, and investigated the antiviral activity of this sample against enterovirus 71 (EV71), as preceived an excellent antiviral capability, together with a compelling biocompatibility. When the CDs solution with $5 \mu \mathrm{g} / \mathrm{mL}$ concentration, was applied on the culture cells, infected by EV71 virus, the inhibition rate against virus-infection exceeded $99 \%$. This level of performance could be gained when concentration of curcumin in culture medium was set at $200 \mu \mathrm{g} / \mathrm{mL}$. In vivo experiments of CDs can outstandingly improve the survival rate of a mice speimen, infected with EV71 virus. Carbon nanotubes [57] have been also looked as anti- virus, but their high cytotoxicity makes their application prospects unclear.

As a two-dimenstional carbon allotrope, graphene oxide has found to be an intresting anti-pathogen. Han et al. [58] reported the broad-spectrum antiviral activity of GO (Fig. 7c) against pseudorabies virus [PRV, a DNA virus (Fig. 7d)] and porcine epidemic diarrhea virus
[PEDV, an RNA virus (Fig. 7e)]. Both GO, and rGO exhibited fascinating antiviral behaviours, arising from their unique single-layer structure and surfacial negative charges. It was inferred that the cell infection by PRV and PEDV can be controlled to two-orders of magnitude, when the concentration of GO, in medium, is set at $6 \mu \mathrm{g} / \mathrm{mL}$. The negatively charged GO showed a higher potential to electrostatically interact with the viruse before entring into the cell, ending to destruction of it's single-layer structure and sharp edges (Fig. 7f). However, the mechanism of antiviral activity in GO remains controversial. Ronit [59] reported that GO inhibits herpes simplex virus type1(HSV-1) infections. They believe that blocking of viral attachment can be the primary antiviral mechanism. Furthermore, combination of carbon-based anti-pathogens with fibers, in application for the face masks, without affecting the physical and chemical properties of carbon molecules, is still challenging and needs to be solved.

\section{Other Inorganic Antiviral Nanoparticles}

Li et al. [60] developed a selenium-adamantine hybrid (Se@ AM) NP, and studied its antiviral properties against the H1N1 influenza virus. In term of morphology, these hybrid NPs featured a uniformly distributed sepherical form, with an average size of $100 \mathrm{~nm}$ (Fig. 8a). In a functional point of view, in presence of this sample, the infection rate of the virus could be controlled by $79 \%$ reduction. Compared with the bare Se NPs with 58\% reduction, the performance of SeNPs was reckoned to be obviously better. This evaluation was carried out based on based on H1N1 influenza virus (Fig. 8b, c). Mateus et al. [61] investigated the biocompatibility and antiviral activity of silica nanoparticles $\left(\mathrm{SiO}_{2}\right)$, with distinct surface properties. Experiments disclosed the antiviral ability of $\mathrm{SiO}_{2}$ NPs against enveloped viruses, which was rule out by attachment inhibition, and suppression of their viral transduction ability.

In addition to the aforementioned inorganic anti-viruses, salt has also a long history in killing microorganisms. Ilaria et al. [62] introduced a reusable virus deactivation system, by functionalization of the center part of the fibrous filtration element of surgical mask, using sodium chloride salt (Fig. 8d). 100\% survival rate was certified, when this system was applied for the virus- infected mices (Fig. 8e). Such an excellence was attributed to the role of PP filtration coating, in adhesion and entrapment of the viral aerosols (Fig. 8f). Destruction mechanism was assigned to the mechanical stresses, from recrystalization of salts, when aerosols loose their liquid phase. 

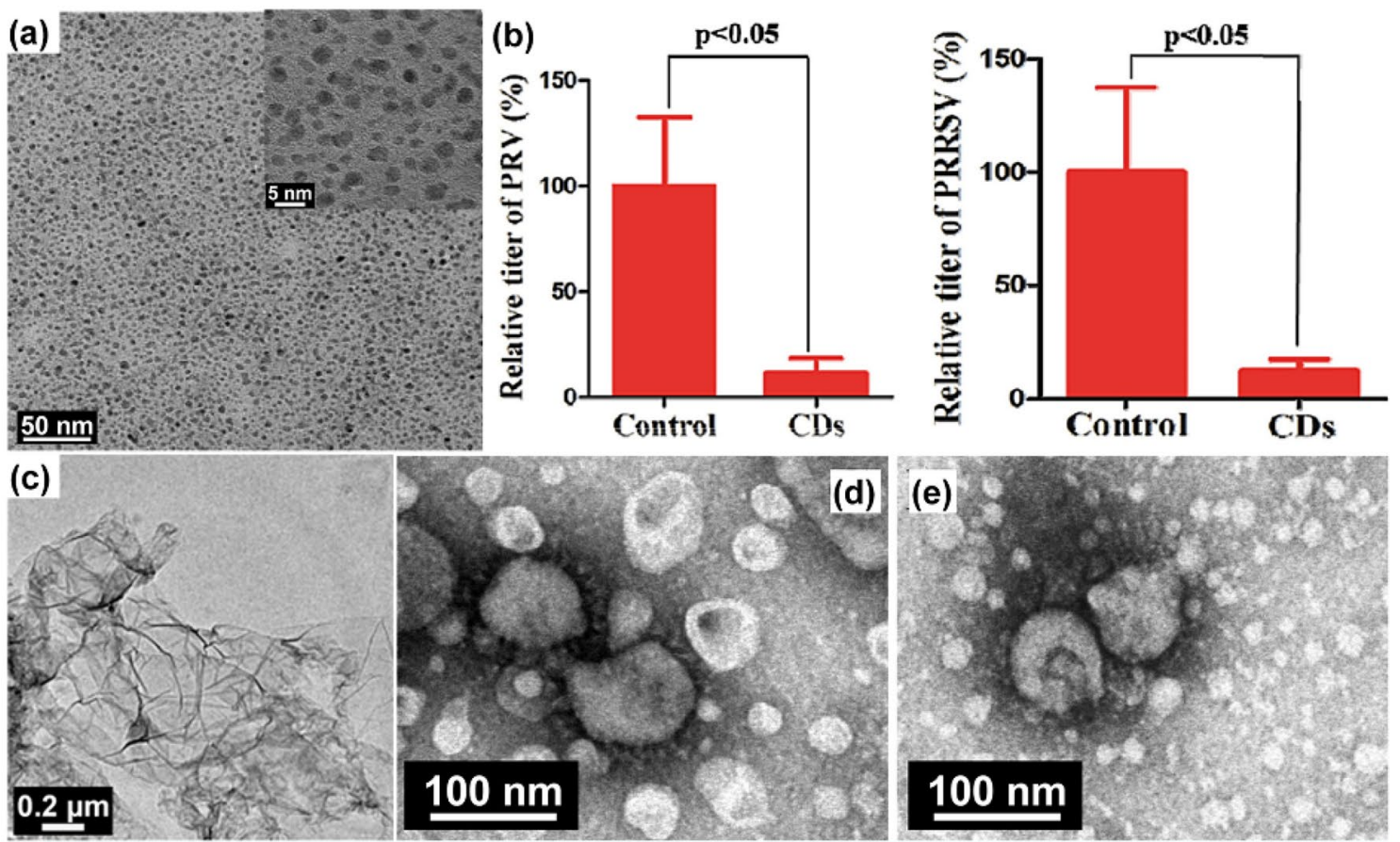

(f)

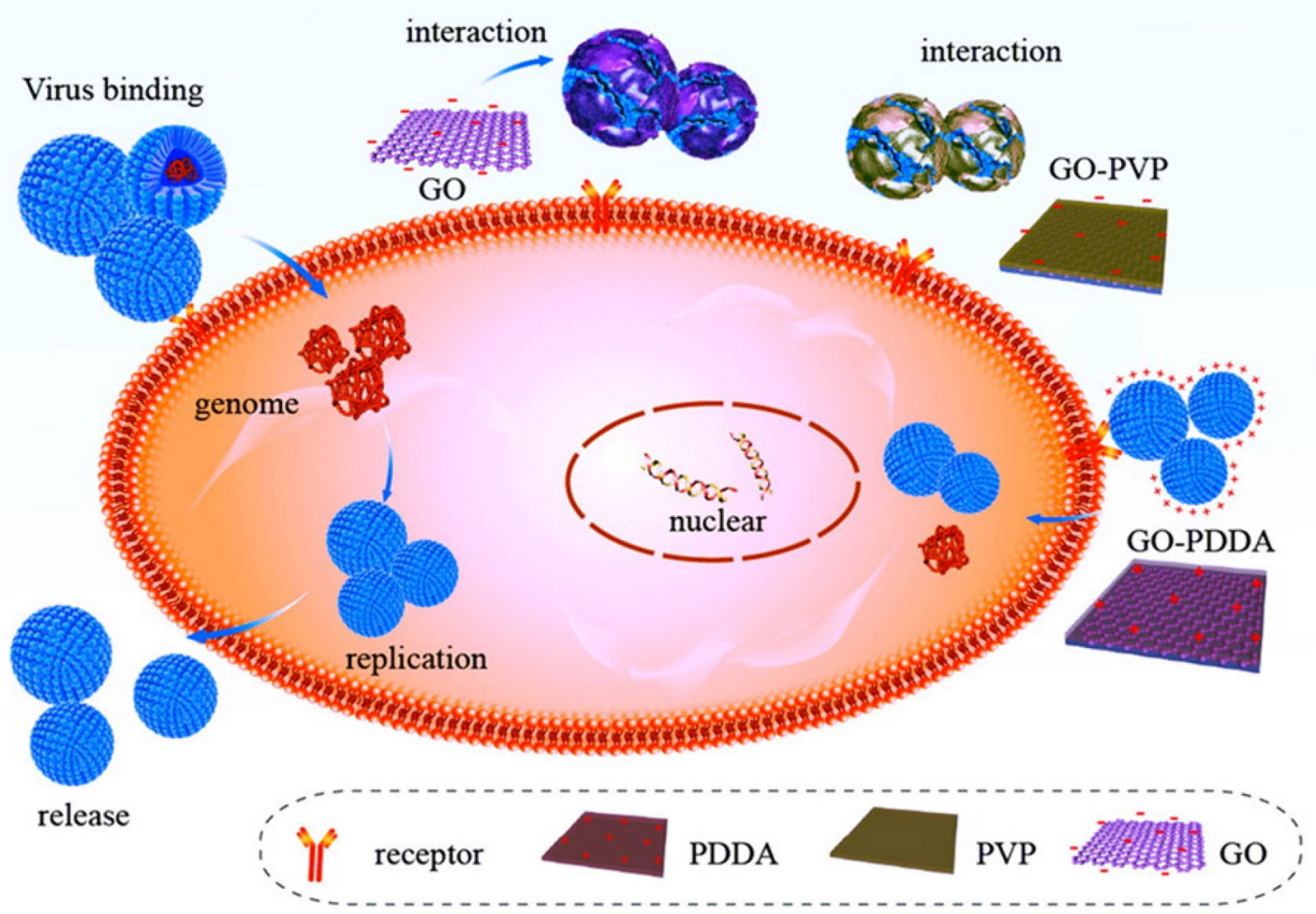

Fig. 7 Carbon-based antiviral materials. a SEM and TEM (inset) images of carbon dots. b Antiviral ability of CDs against PRRSV and PRV. a, b Reproduced with permission from Ref. [55]. Copyright 2016 Elsevier. c Morphology of GO. d Morphology of PRV treated with GO, for $1 \mathrm{~h}$. e The morphology of PEDV incubated with GO, for 1 h. f Mechanisms of antiviral activity of GO. c-f Reproduced with permission from Ref. [58]; Copyright 2015 American Chemical Society 

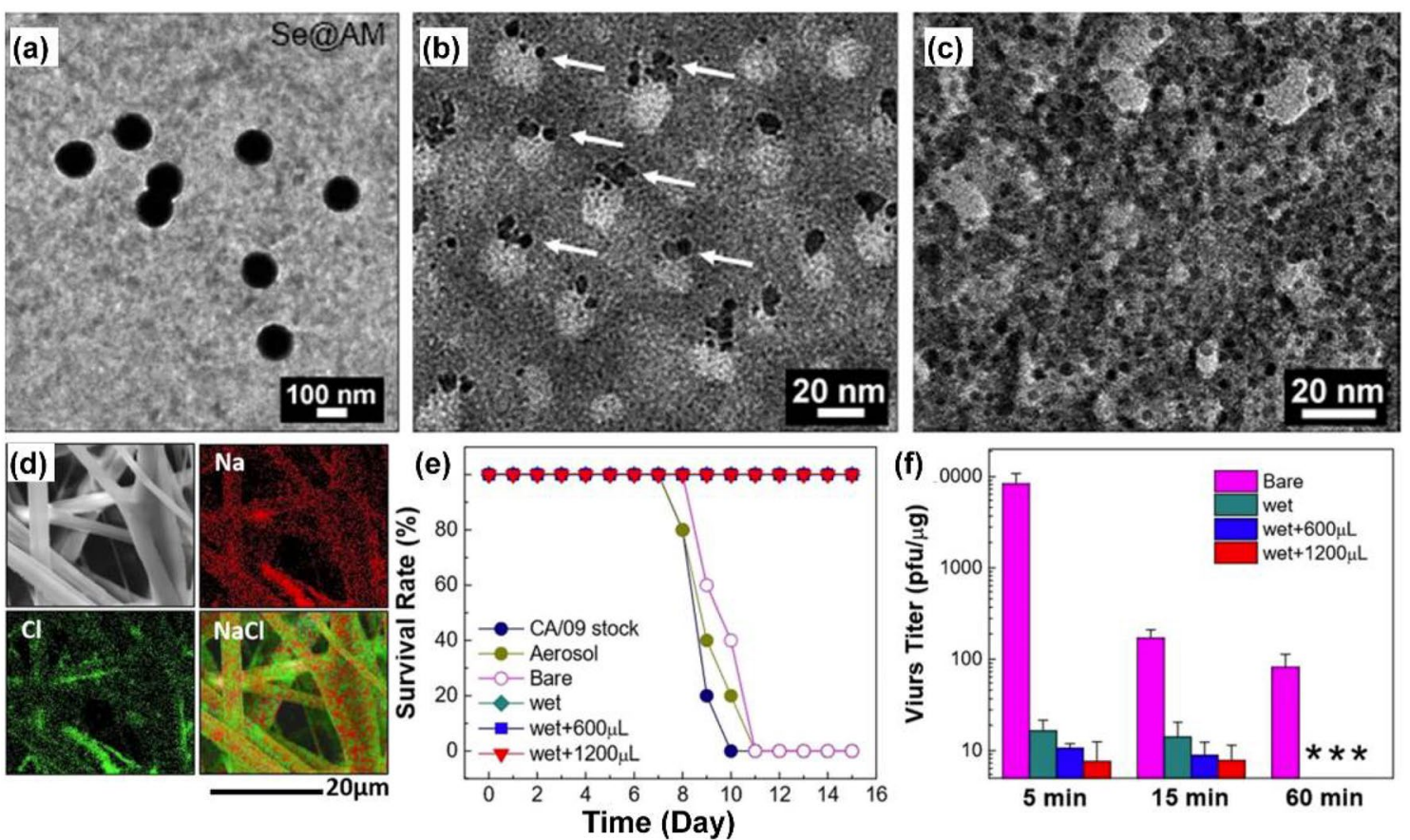

Fig. 8 Inorganic antiviral nanoparticles. a SEM image of Se@AM. b Morphology of Se@AM attached to H1N1. c Morphologic abnormalities in Se@AM-treated H1N1. a-c Reproduced with permission from Ref. [60]. Copyright 2018 Taylor and Francis. d Morphology

and elemental distribution pattern of filter containing $\mathrm{NaCl}$. e Inhibition of virus activity. $\mathbf{f}$ Influence of incubation status on the the active life-time of viruses. d-f Reproduced with permission from Ref. [62]; Copyright 2017 Springer Nature

Table 2 Comparison of the organic antiviral materials

\begin{tabular}{|c|c|c|c|}
\hline Types & Performance & Mechanism of antiviral & References \\
\hline$N$-halamine & $\begin{array}{l}\text { Contact with } 0.5 \% \mathrm{~N} \text {-halamine for } 30 \mathrm{~min} \text {, } \\
\text { the infection rate reduce seven orders of } \\
\text { magnitude }\end{array}$ & Interrupt RNA specific sites & {$[63]$} \\
\hline $\mathrm{N}, \mathrm{N}$-dodecyl methylpolyethylenimines (PEIs) & $\begin{array}{l}\text { Kill the influenza virus with essentially } 100 \% \\
\text { efficiency within minutes }\end{array}$ & Damage lipid membrane & {$[64]$} \\
\hline Chitosan & $\begin{array}{l}\text { At concentration of } 1 \mathrm{~g} / \mathrm{L} \text { inhibited the infec- } \\
\text { tion of NCV }\end{array}$ & Stimulation of immune response & {$[66]$} \\
\hline $\begin{array}{l}\text { Zinc-tetra(4- } N \text {-methylpyridyl)porphine } \\
\left(\mathrm{ZnTMPyP}^{4+}\right)\end{array}$ & $\begin{array}{l}\text { After exposure to light for } 60 \text { min, inactivat- } \\
\text { ing bacterial and viruses at least } 99.89 \% \text { and } \\
99.95 \%\end{array}$ & Production of ROS & [71] \\
\hline Sunlight active nanofiber membranes & $\begin{array}{l}\text { Killing rate of bacteria and viruses higher than } \\
99 \%\end{array}$ & Production of ROS & {$[73]$} \\
\hline
\end{tabular}

\section{Organic Antiviral Materials}

Organic antiviral materials kill pathogens by the reaction on the surface proteins or nucleic acids, or destroy the morphology or proliferation of pathogens, via generation of reactive oxygen species (ROS), under external stimulation. Based on their anti-microbial function, the organic antiviral materials can be divided to antiviral and photodynamic antiviral materials. Table 2 summarizes and compares the different types of the organic antiviral systems.

\section{Intrinsic Antiviral Materials}

Intrinsic antiviral material can lead to virus inactivation due to their chemical structure. As shown in Fig. 9a, many synthetic and natural compounds have intrinsic antiviral properties. $\mathrm{N}$-halamine is an effective organic synthetic antibacterial material, which is widely used for antibacterial 

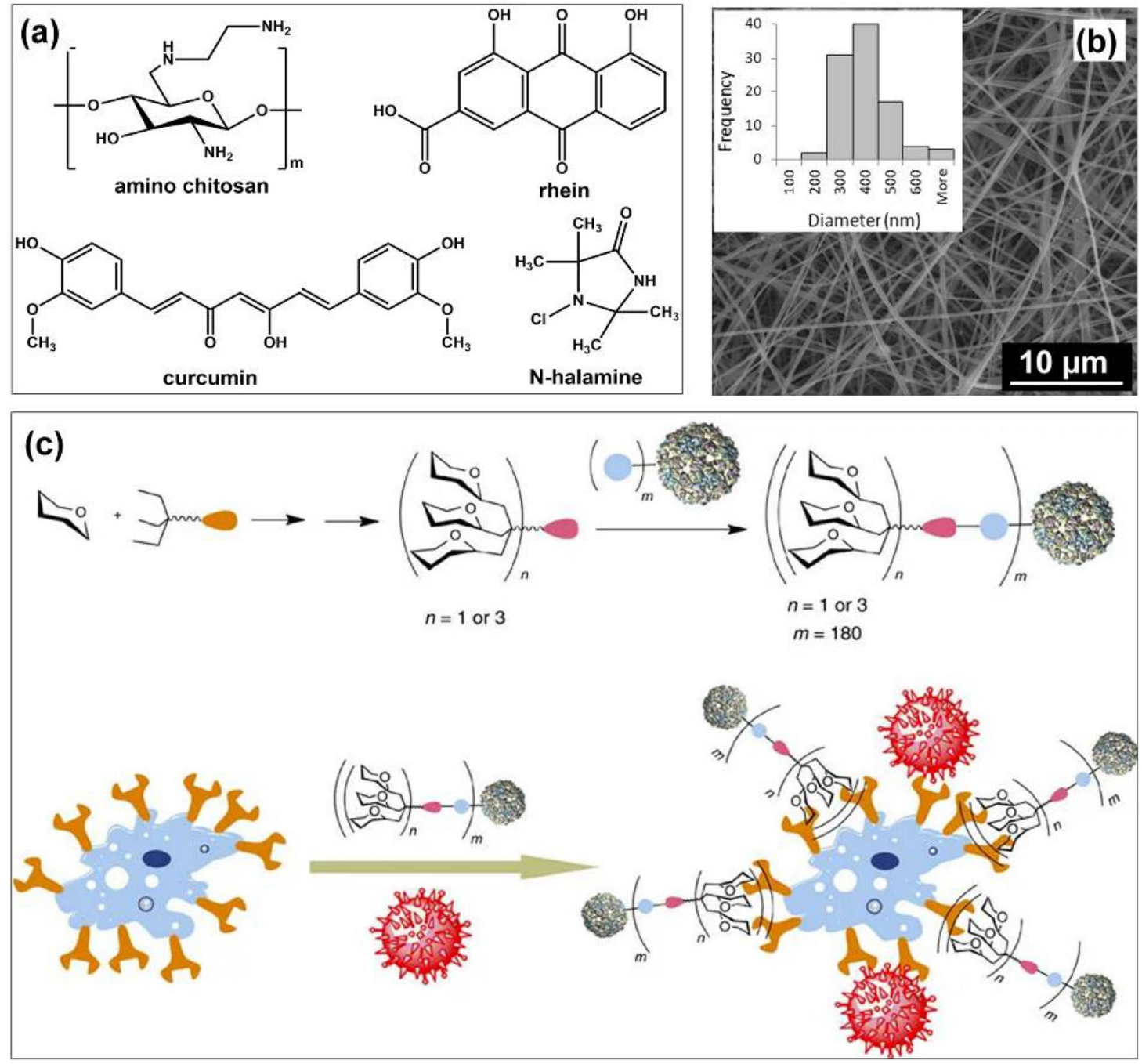

Fig. 9 Intrinsic antiviral materials. a Chemical structures of intrinsic antiviral substances. b Morphology of chitosan nanofibrous mats. Inset is distribution of fiber diameter. a, b Reproduced with permis-

modification of fibers, but its antiviral properties have been rarely studied. Ren et al. [63] propose $N$-halamine coating on the surface of non-woven fabrics to obtain fabric materials with antibacterial and antiviral activity. They remark that the deposited $N$-halamine was stable, non-volatile, and caused an efficient antiviral activity. After being exposed to $0.5 \%$ $\mathrm{N}$-halamine for $30 \mathrm{~min}$, the infection rate of the virus was reduced to seven orders of magnitude. $N$-halamine could kill the AI viruses in a short matter of time, with disrupting its genetic and replication capabilities. This function was managed by destruction of the specific active sites on the viral RAN. The hydrophilicity of the surface is also a crucial factor of antiviral ability. Organic materials are often used to sion from Ref. [67]. Copyright 2019 Elsevier. c Schematic virus-like glycodendrinanoparticles and their function. c Reproduced with permission from Ref. [65]; Copyright 2012 Springer Nature

change the hydrophilicity of the surface of various protective materials. In order to obtain a hydrophobic surface, Jayanta et al. [64] synthesized the branched or linear hydrophobic N, $\mathrm{N}$-dodecyl methylpolyethylenimines (PEIs) and verified their antiviral activity against influenza virus. The hydrophobic PEIS could kill the influenza virus, as well as E. coli and S. aureus, with $100 \%$ efficiency, in few minutes. Hydrophobic PEIS can damage the lipid membrane of the virus by erecting fragments of the polycationic chains ("tentacles"). On the other hand, the organic materials are used for assembling the virus-mimic which can effectively interact with receptors and inhibit the invasion of viruses to the host cells. Renato et al. [65] reported a virus-like glycodendric nanoparticles 
assembled with highly valent glycodendrimeric, condtructed via nested layers of multivalency. The surface of glycodendrinanoparticles is highly glycosylated and up to $32 \mathrm{~nm}$ in diameter, mimicking the size and surface of a pathogen. The glycodendrimeri-nanoparticles sample which could prevent infection of T-lymphocytes and human dendritic cells by the Ebola virus (inhibition rate $>80 \%$ ), through competitive blockage of the DC-SIGN (dendritic cell-specific intercellular adhesion molecule-3-grabbing nonintegrin, one of the most important pathogen recognition receptor) (Fig. 9c).

In addition to the above synthetic compounds or specific compound structures, there are still many natural compounds with prominent antiviral activity. He et al. [66] studied the antiviral properties of chitosan materials. They synthesized 6-deoxy-6-bromo- $N$-phthaloyl chitosan and tested its antiviral activity. Additionally, they indicated that chitosan derivatives showed excellent antiviral activity. At a chitosan derivative concentration of $1 \mathrm{~g} / \mathrm{L}$, the infection of NCV was completely inhibited through the stimulation of an immune response. In order to study the application of chitosan in biomedical engineering, Khorasani [67] fabricated chitosan nanofibrous mats using the electrospinning method and investigated the ability to kill pathogens (Fig. 9b). The results showed that the nanofiber mats had a broad-spectrum antibacterial effect, but the related antiviral ability was not mentioned. Other natural compounds such as R. tanguticum nanoparticles [68], catechins [69], and curcumin [70] had also been shown to have excellent killing abilities against various viruses.

\section{Photodynamic Antiviral Materials}

Photodynamic antiviral materials are usually driven by light, to produce reactive oxygen species (ROS), which can selectively kill the pathogens. Photodynamic antiviral materials can achieve efficient, broad-spectrum and longacting killing of pathogens, and are safe for the environment. Therefore, they have a great potential in preparation of biological protection materials. Richard et al. [71] explored the anti-infective efficacy of films containing zinc-tetra(4$\mathrm{N}$-methylpyridyl)porphine (ZnTMPyP ${ }^{4+}$, photoactive substance). After exposure to the light for $60 \mathrm{~min}$, this photodynamic polymer was capable of inactivating both bacteria and viruses, with the rates of $99.89 \%$ and $99.95 \%$, respectively. Production of ROS is the main mechanism for the efficient killing of microorganisms, in this system. When photodynamic materials are used in fibers, their compatibility with fibers, the life-time of photosensitizer and the diffusion range of reactive oxygen species will affect their antiviral properties. Encapsulation of photosensitizer can effectively improve the compatibility and prolong the life-time of the photosensitizer. Mosinger et al. [72] prepared a stable photoactive nanoparticle sample by covering of photosensitizer with polyethylene. The polyethylene nanofiber membrane was prepared by electrostatic spinning and used to encapsulate the photosensitizer. The nanofiber membrane inhibited the function of both bacteria and viruses, by more than $99 \%$, after a short exposure to visible light.

Also, the solely photo-driven biocidal character of photo antiviral materials leads to the instantaneous biocidal function of fast decaying or quenching under dim light and dark conditions. Thus, it is necessary to solve the decrease of killing efficiency in a dyssophotic environment. Sun et al. [73] prepared nanofiber membranes driven by daylight with high antiviral activity, via electrostatic spinning (Fig. 10a, b). The nanofiber membranes yielded $99 \%$ killing rate on both virus and bacteria, based on ROS production (Fig. 10c). The nanofiber membrane could also generate and retain it's biological activity in sunlight. They additionally, considered the application of this antiviral nanofiber membrane in bioprotective equipment, and studied the ability of the issuing equipment, for interception effect on aerosols, and killing the trapped pathogens (Fig. 10d). Results showed that the filtration performance of the nanofiber membrane values with current commercialized filtration materials, as could kill $100 \%$ of the trapped pathogens.

\section{Conclusions and Perspectives}

Currently, antiviral personal protective devices, especially the face masks, have received considerable attentions, in both academic and industrial fields of research. Most of the commercial masks are unable to suffciently filter the tiny aerogels containing the viruses. On the other hand, viruses which are attached to the filtering materials can penetrate through the moist mask, and in this way increase the risk of infection. This mini-review looks into the most recent advances in antiviral agents, and the methods which are used for preparation of protective materials. Improving the antiviral capability of the face masks, can reduce the risk of cross-infection or secondary infection during the useage or handling. Recent progresses in this field indicate that nanotechnology can foumdamentally evolves the structure and effcetiveness of the current respiratory protection devices.

To date, thousands of nanomaterials and nanotechnologyrelated procedures serve the trend of this progression, as discussed here. Different potential anti-microbial systems, which are integrable into the face masks are introduced in this work. Also, various anti-infection mechanisms, including attachment blocking, reproduction inhibitory action and deformation of 
(a)

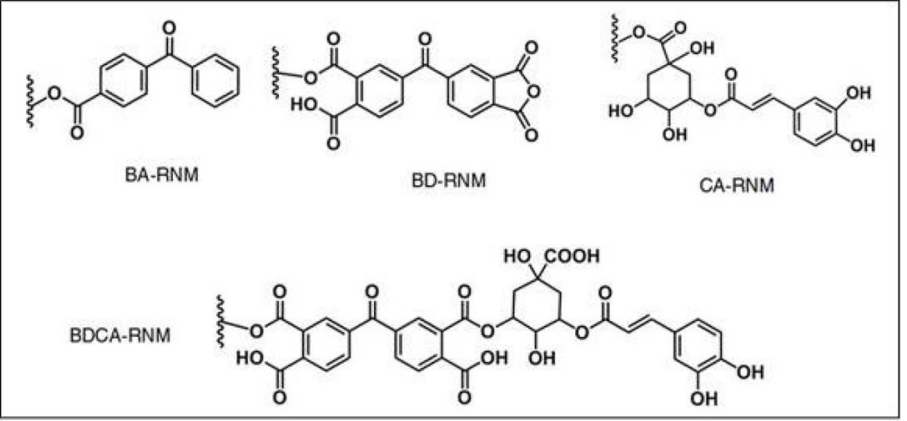

(b)

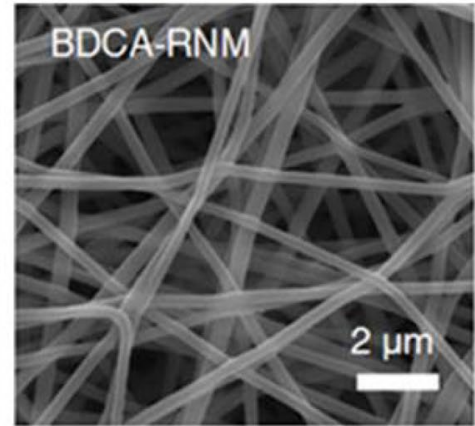

(c)

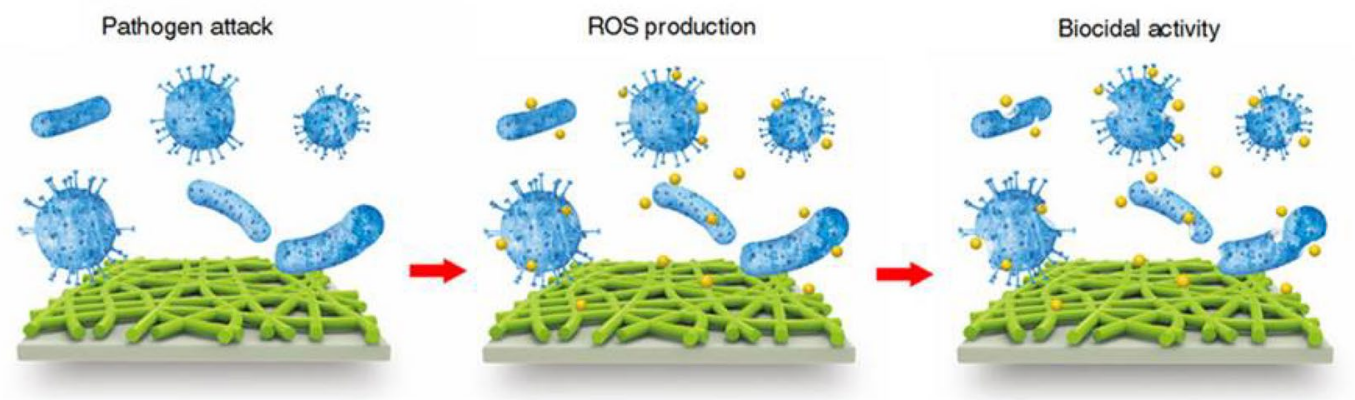

(d)
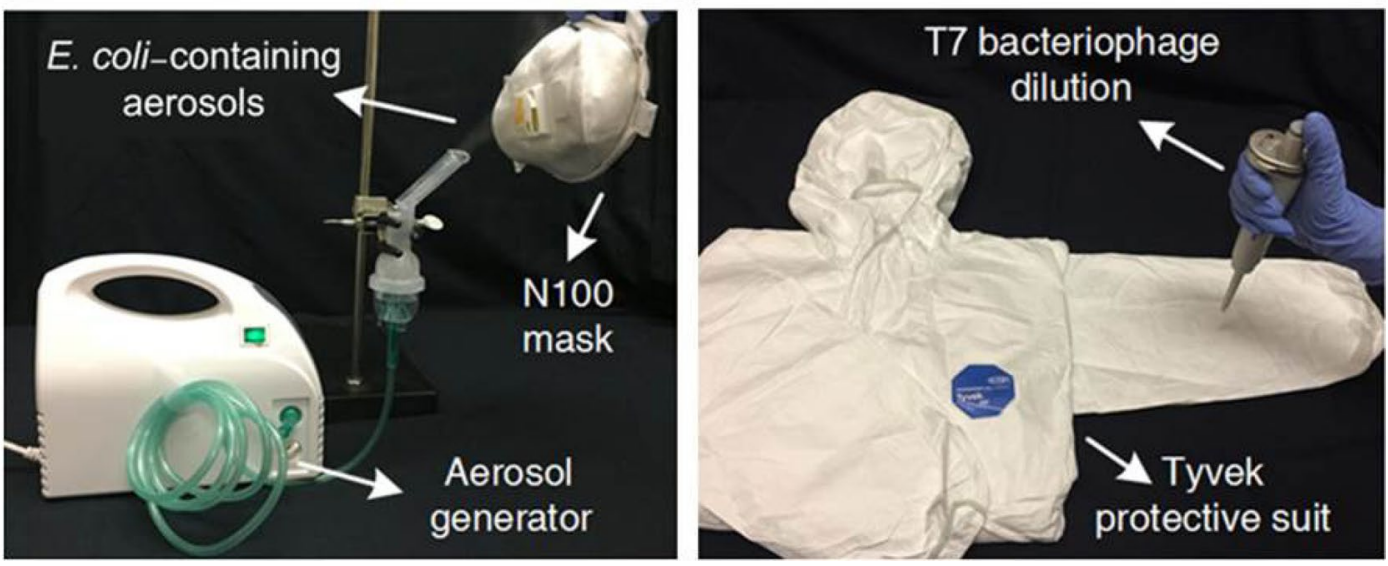

Fig. 10 Photodynamic antiviral materials. a, b Chemical structure and SEM image of photo-active nanofiber membranes. c Schematic demonstration of biocidal function of nanofiber membrane. d Appli-

the virial wall and membrane are highlighted. As a closing point, this review shed a light to the current shortcomings in personal protective facilities, which are lack of enough comfort, high efficiency, safety and intelligence (Fig. 11). These serious setbacks can solve by (1) product engineering, to be adapted with human face, skin and body, and to controlling the, unwanted affcets such as accumulation of heat and moisture during usage; (2) to improve the filtering efficiency cation of antiviral fibers in mask and protective suit. Panels in this figure reproduced with permission from Ref. [73]. Copyright 2018 AAAS

and breathing, without risks, by tuning of the structural factors, such as diameter of the fibers size of the holes, and thickness of the filtering materials; (3) to apply the nanotechnology-related procedures in order to augment the entrapting potential, antiviral capabilities and intelligence of protective equipment. Finally, the functional integration and engineering of protective devices are currently unsystematic, and further research and study are required. 


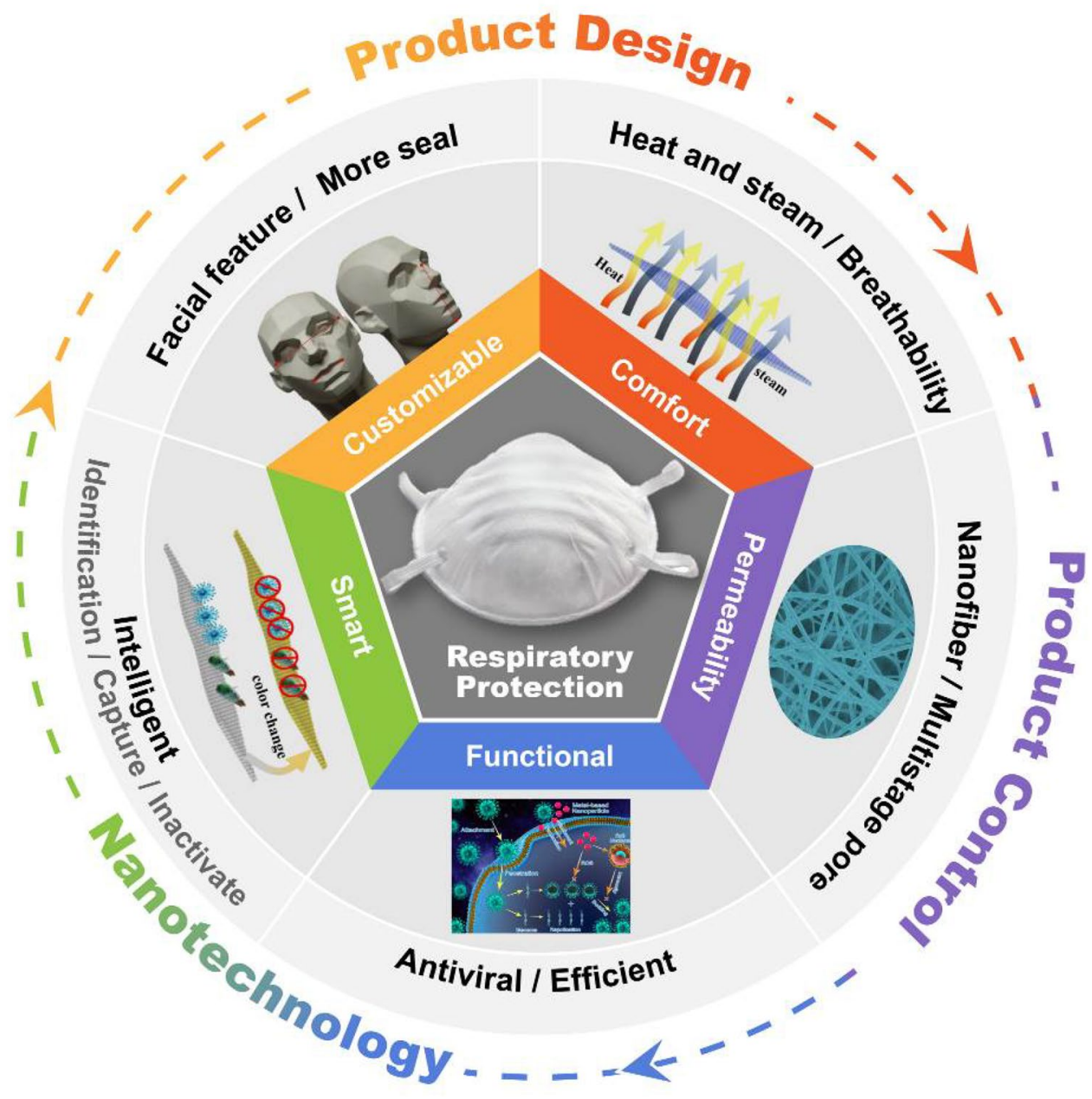

Fig. 11 Graphical expression of future development prospect of respiratory protection devices

Acknowledgements This work was financially supported by the National Key Research and Development Program of China (2016YFA0201702 and 2016YFA0201700), the National Natural Science Foundation of China (51972056, 51773036), Innovation Program of Shanghai Municipal Education Commission (2017-01-07-00-03E00055), Shanghai Belt and Road Joint Laboratory of Advanced Fiber and Low-dimension Materials (18520750400), China Postdoctoral Science Foundation (2019M661323), the Fundamental Research Funds for the Central Universities.

\section{Compliance with Ethical Standards}

Conflict of interest The authors declare that there is no financial and non-financial competing interest.

\section{References}

1. Metcalf E, Lessler J. Opportunities and challenges in modeling emerging infectious diseases. Science. 2017;357:149.

2. https://voice.baidu.com/act/newpneumonia/newpneumon ia/?from=osari_pc_1. Accessed 16 Feb 2020.
3. Na Z, Dingyu Z, Wenling W, Xinwang L, Bo Y, Jingdong S, Xiang Z, Baoying H, Weifeng S, Roujian L, Peihua N, Faxian Z, Xuejun M, Dayan W, Wenbo X, Guizhen W, George G, Wenjie T. A novel coronavirus from patients with pneumonia in China, 2019. N Engl J Med. 2020. https://doi.org/10.1056/ NEJMoa2001017.

4. Zhou P, Yang XL, Wang XG, Hu B, Zhang L, Zhang W, Si HR, Zhu Y, Li B, Huang CL, Chen HD, Chen J, Luo Y, Guo H, Jiang RD, Liu MQ, Chen Y, Shen XR, Wang X, Zheng XS, Zhao K, Chen QJ, Deng F, Liu LL, Yan B, Zhan FX, Wang YY, Xiao GF, Shi ZL. A pneumonia outbreak associated with a new coronavirus of probable bat origin. Nature. 2020;579:270.

5. Rubino I, Hyo C. Respiratory protection against pandemic and epidemic diseases. Trends Biotechnol. 2017;35:907.

6. Oberg T, Brosseau L. Surgical mask filter and fit performance. Am J Infect Control. 2008;36:276.

7. Iwata M, Tanizaki H, Fujii H, Endo Y, Fujisawa A, Tanioka M, Miyachi Y, Kabashima K. Contact urticaria due to a face mask coated with disinfectant liquid spray. Acta Derm Venereol. 2015;95:628.

8. Winski T, Mueller W, Graveling R. If the mask fits: facial dimensions and mask performance. Int J Ind Ergonom. 2019;72:308. 
9. Parthasarathi V, Thilagavathi G. Development of plasma enhanced antiviral surgical gown for healthcare workers. Fash Text. 2015;2:1.

10. Li Y, Leung P, Yao L, Song Q, Newton E. Antimicrobial effect of surgical masks coated with nanoparticles. J Hosp Infect. 2006; $62: 58$

11. Habibzadeh P, Stoneman E. The novel coronavirus: a bird's eye view. Int J Occup Med Environ. 2020;11:65.

12. Galdiero S, Falanga A, Vitiello M, Cantisani M, Marra V, Galdiero M. Silver nanoparticles as potential antiviral agents. Molecules. 2011; $16: 8894$.

13. Orlowski P, Kowalczyk A, Tomaszewska E, Ranoszek-Soliwoda K, Wegrzyn A, Grzesiak J, Celichowski G, Grobelny J, Eriksson K, Krzyzowska M. Antiviral activity of tannic acid modified silver nanoparticles: potential to activate immune response in herpes genitalis. Viruses-Basel. 2018;10:524.

14. Tran Quang H, Nguyen Thi Hien T, Nguyen Thanh T, Pham Van C, Pham Ngoc H, Anh-Tuan L, Nguyen Thi Hong H. Cytotoxicity and antiviral activity of electrochemical-synthesized silver nanoparticles against poliovirus. J Virol Methods. 2017;241:52.

15. Lara H, Ayala-Nunez N, Ixtepan-Turrent L, Rodriguez-Padilla C. Mode of antiviral action of silver nanoparticles against HIV-1. $J$ Nanobiotechnol. 2010;8:1.

16. Morris D, Ansar M, Speshock J, Ivanciuc T, Yue Q, Casola A, Garofalo R. Antiviral and immunomodulatory activity of silver nanoparticles in experimental RSV infection. Viruses-Basel. 2019; 11:732.

17. Sharma V, Kaushik S, Pandit P, Dhull D, Yadav J, Kaushik S. Green synthesis of silver nanoparticles from medicinal plants and evaluation of their antiviral potential against chikungunya virus. Appl Microbiol Biotechnol. 2019;103:881.

18. Li Y, Lin Z, Zhao M, Xu T, Wang C, Hua L, Wang H, Xia H, Zhu B. Silver nanoparticle based codelivery of oseltamivir to inhibit the activity of the H1N1 influenza virus through ROS-mediated signaling pathways. ACS Appl Mater Interfaces. 2016;8:24385.

19. Li Y, Lin Z, Zhao M, Guo M, Xu T, Wang C, Xia H, Zhu B. Reversal of H1N1 influenza virus-induced apoptosis by silver nanoparticles functionalized with amantadine. RSC Adv. 2016; 6:89679.

20. Lin Z, Li Y, Guo M, Xu T, Wang C, Zhao M, Wang H, Chen T, Zhu B. The inhibition of H1N1 influenza virus-induced apoptosis by silver nanoparticles functionalized with zanamivir. RSC Adv. 2017; 7:7420.

21. Santos Pereira A, Nakahata D, Manzano C, Alencar Simoni D, Pereira D, Lustri W, Formiga A, Corbi P. Synthesis, crystallographic studies, molecular modeling and in vitro biological studies of silver(I) complexes with aminoadamantane ligands. Polyhedron. 2019;173:114.

22. Du T, Liang J, Dong N, Lu J, Fu Y, Fang L, Xiao S, Han H. Glutathione-Capped $\mathrm{Ag}_{2} \mathrm{~S}$ nanoclusters inhibit coronavirus proliferation through blockage of viral RNA synthesis and budding. ACS Appl Mater Interfaces. 2018; 10:4369.

23. Seifullina I, Martsinko E, Gridina T, Chebanenko E, Mudrik L, Fedchuk A. Antiviral properties of the new coordination compound silver bis(citrato)germanate. Pharm Chem J. 2019;53:318.

24. Plotnikov E, Silnikov V, Gapeyev A, Plotnikov V. Investigation of DNA-damage and chromosomal aberrations in blood cells under the influence of new silver-based antiviral complex. Adv Pharm Bull. 2016;6:71.

25. Cavicchioli M, Massabni A, Heinrich T, Costa-Neto C, Abrao E, Fonseca B, Castellano E, Corbi P, Lustri W, Leite C. Pt(II) and $\mathrm{Ag}(\mathrm{I})$ complexes with acesulfame: crystal structure and a study of their antitumoral, antimicrobial and antiviral activities. J Inorg Biochem. 2010;104:533.
26. Tang B, Li J, Hou X, Afrin T, Sun L, Wang X. Colorful and antibacterial silk fiber from anisotropic silver nanoparticles. Ind Eng Chem Res. 2013;2:4556.

27. Jiang S, Qin W, Guo R, Zhang L. Surface functionalization of nanostructured silver-coated polyester fabric by magnetron sputtering. Surf Coat Technol. 2010;204:3662.

28. Wu M, Ma B, Pan T, Chen S, Sun J. Silver-nanoparticle-colored cotton fabrics with tunable colors and durable antibacterial and self-healing superhydrophobic properties. Adv Funct Mater. 2016;26:569.

29. Ali S, Rajendran S, Joshi M. Synthesis and characterization of chitosan and silver loaded chitosan nanoparticles for bioactive polyester. Carbohydr Polym. 2011;83:438.

30. Lévy R, Thanh N, Doty R, Hussain I, Nichols R, Schiffrin D, Brust M, Fernig D. Rational and combinatorial design of peptide capping ligands for gold nanoparticles. J Am Chem Soc. 2004; $126: 10076$.

31. Melendez-Villanueva M, Moran-Santibanez K, Martinez-Sanmiguel J, Rangel-Lopez R, Garza-Navarro M, Rodriguez-Padilla C, Zarate-Trivino D, Trejo-Avila L. Virucidal activity of gold nanoparticles synthesized by green chemistry using garlic extract. Viruses-Basel. 2019;11:1111.

32. Papp I, Sieben C, Ludwig K, Roskamp M, Boettcher C, Schlecht $S$, Herrmann A, Haag R. Inhibition of influenza virus infection by multivalent sialic-acid-functionalized gold nanoparticles. Small. 2010;6:2900.

33. Naruse Y. Surface functionalization of gold nanoparticles for antiviral medicines by simulating the surface structure of host cells. $J$ Basic Appl Sci. 2015;11:572.

34. Tao W, Hurst B, Shakya A, Uddin M, Ingrole R, HernandezSanabria M, Arya R, Bimler L, Paust S, Tarbet E. Consensus $\mathrm{M} 2 \mathrm{e}$ peptide conjugated to gold nanoparticles confers protection against H1N1, H3N2 and H5N1 influenza A viruses. Antivir Res. 2017;141:62.

35. Chakravarthy K, Bonoiu A, Davis W, Ranjan P, Ding H, Hu R, Bowzard J, Bergey E, Katz J, Knight P. Gold nanorod delivery of an ssRNA immune activator inhibits pandemic H1N1 influenza viral replication. Proc Natl Acad Sci USA. 2010;107:10172.

36. Li C, Zheng L, Yang X, Wan X, Wu W, Zhen S, Li Y, Luo L, Huang C. DNA-AuNP networks on cell membranes as a protective barrier to inhibit viral attachment, entry and budding. Biomaterials. 2016;77:216.

37. Bawage S, Tiwari P, Singh A, Dixit S, Pillai S, Dennis V, Singh S. Gold nanorods inhibit respiratory syncytial virus by stimulating the innate immune response. Nanomed-Nanotechnol. 2016; $12: 2299$.

38. Carja G, Grosu E, Petrarean C, Nichita N. Self-assemblies of plasmonic gold/layered double hydroxides with highly efficient antiviral effect against the hepatitis B virus. Nano Res. 2015;8:3512.

39. Zhou J, Xiang H, Zabihi F, Yu S, Sun B, Zhu M. Intriguing antisuperbug $\mathrm{Cu}_{2} \mathrm{O} @ \mathrm{ZrP}$ hybrid nanosheet with enhanced antibacterial performance and weak cytotoxicity. Nano Res. 2019;12:1453.

40. Zhou J, Wang C, Cunningham A, Hu Z, Xiang H, Sun B, Zuo W, $\mathrm{Zhu} \mathrm{M}$. Synthesis and characterization of size-controlled nano$\mathrm{Cu}_{2} \mathrm{O}$ deposited on alpha-zirconium phosphate with excellent antibacterial property. Mater Sci Eng C Mater. 2019;101:499.

41. Tavakoli A, Hashemzadeh M. Inhibition of herpes simplex virus type 1 by copper oxide nanoparticles. J Virol Methods. 2020;275: 113688.

42. Borkow G, Steve Z, Page T, Gabbay J. A novel anti-influenza copper oxide containing respiratory face mask. PLoS One. 2010;5:1.

43. Hang X, Peng H, Song H, Qi Z, Miao X, Xu W. Antiviral activity of cuprous oxide nanoparticles against hepatitis $\mathrm{C}$ virus in vitro. J Virol Methods. 2015;222:150. 
44. Mazurkow J, Yuzbasi N, Domagala K, Pfeiffer S, Kata D, Graule T. Nano-sized copper (oxide) on alumina granules for water filtration: effect of copper oxidation state on virus removal performance. Environ Sci Technol. 2020;54:1214.

45. Minoshima M, Lu Y, Kimura T, Nakano R, Ishiguro H, Kubota Y, Hashimoto K, Sunada K. Comparison of the antiviral effect of solid-state copper and silver compounds. J Hazard Mater. 2016;312:1

46. Fujimori Y, Sato T, Hayata T, Nagao T, Nakayama M, Nakayama T, Sugamata R, Suzuki K. Novel antiviral characteristics of nanosized copper(I) iodide particles showing inactivation activity against 2009 pandemic H1N1 influenza virus. Appl Environ Microbiol. 2012;78:951.

47. Sunada K, Minoshima M, Hashimoto K. Highly efficient antiviral and antibacterial activities of solid-state cuprous compounds. J Hazard Mater. 2012;235:265.

48. Mishra Y, Adelung R, Roehl C, Shukla D, Spors F, Tiwari V. Virostatic potential of micro-nano filopodia-like $\mathrm{ZnO}$ structures against herpes simplex virus-1. Antivir Res. 2011;92:305.

49. Cai L, Liu C, Fan G, Liu C, Sun X. Preventing viral disease by ZnONPs through directly deactivating TMV and activating plant immunity in Nicotiana benthamiana. Environ Sci Nanotechnol. 2019;6:3653.

50. Tavakoli A, Ataei-Pirkooh A, Sadeghi G, Bokharaei-Salim F, Sahrapour P, Kiani S, Moghoofei M, Farahmand M, Javanmard D, Monavari S. Polyethylene glycol-coated zinc oxide nanoparticle: an efficient nanoweapon to fight against herpes simplex virus type 1. Nanomedicine. 2018;13:2675.

51. Akhtar S, Shahzad K, Mushtaq S, Ali I, Rafe M, Fazal S. Antibacterial and antiviral potential of colloidal titanium dioxide $\left(\mathrm{TiO}_{2}\right)$ nanoparticles suitable for biological applications. Mater Res Express. 2019;6:105409.

52. Trigilio J, Antoine T, Paulowicz I, Mishra Y, Adelung R, Shukla D. Tin oxide nanowires suppress herpes simplex virus-1 entry and cell-to-cell membrane fusion. PLoS One. 2012;7:48147.

53. Soto E, O'Connell O, Dikengil F, Peters P, Clapham P, Ostroff G. Targeted delivery of glucan particle encapsulated gallium nanoparticles inhibits HIV growth in human macrophages. $J$ Drug Deliv. 2016;2016:8520629.

54. Ryoo S, Jang H, Kim K, Lee B, Kim K, Kim Y, Yeo W, Lee Y, Kim D, Min D. Functional delivery of DNAzyme with iron oxide nanoparticles for hepatitis $\mathrm{C}$ virus gene knockdown. Biomaterials. 2012;33:2754.

55. Du T, Liang J, Dong N, Liu L, Fang L, Xiao S, Han H. Carbon dots as inhibitors of virus by activation of type I interferon response. Carbon. 2016;110:278.

56. Lin C, Chang L, Chu H, Lin H, Chang P, Wang R, Unnikrishnan B, Mao J, Chen S, Huang C. High amplification of the antiviral activity of curcumin through transformation into carbon quantum dots. Small. 2019; 15:1902641.

57. Chen H, Humes S, Robinson S, Loeb J, Sabaraya I, Saleh N, Khattri R, Merritt M, Martyniuk C, Lednicky J, Sabo-Attwood T. Single-walled carbon nanotubes repress viral-induced defense pathways through oxidative stress. Nanotoxicology. 2019; $13: 1176$.

58. Ye S, Shao K, Li Z, Guo N, Zuo Y, Li Q, Lu Z, Chen L, He Q, Han H. Antiviral activity of graphene oxide: how sharp edged structure and charge matter. ACS Appl Mater Interfaces. 2015; 7:21571.

59. Sametband M, Kalt I, Gedanken A, Sarid R. Herpes simplex virus type-1 attachment inhibition by functionalized graphene oxide. ACS Appl Mater Interfaces. 2014;6:1228.

60. Li Y, Lin Z, Guo M, Zhao M, Xia Y, Wang C, Xu T, Zhu B. Inhibition of H1N1 influenza virus-induced apoptosis by functionalized selenium nanoparticles with amantadine through ROSmediated AKT signaling pathways. Int J Nanomed. 2018;13:2005.

61. Silva J, Hanchuk T, Santos M, Kobarg J, Bajgelman M, Cardoso M. Viral inhibition mechanism mediated by surface-modified silica nanoparticles. ACS Appl Mater Interfaces. 2016;8:16564.

62. FuShi Q, Rubino R, SuHwa L, Brendan K, HyoJick C. Universal and reusable virus deactivation system for respiratory protection. Sci Rep. 2017;7:39956.

63. Ren T, Dormitorio T, Qiao M, Huang T, Weese J. N-halamine incorporated antimicrobial nonwoven fabrics for use against avian influenza virus. Vet Microbiol. 2018;218:78.

64. Haldar J, An D, Cienfuegos L, Chen J, Klibanov A. Polymeric coatings that inactivate both influenza virus and pathogenic bacteria. Proc Natl Acad Sci USA. 2006;103:17667.

65. Ribeiro R, Sanchez M, Luczkowiak J, Koeppe J, Delgado R, Rojo J, Davis B. Virus-like glycodendrinanoparticles displaying quasi-equivalent nested polyvalency upon glycoprotein platforms potently block viral infection. Nat Commun. 2012;3:2302.

66. He X, Xing R, Liu S, Qin Y, Li K, Yu H, Li P. The improved antiviral activities of amino-modified chitosan derivatives on Newcastle virus. Drug Chem Toxicol. 2019;1:1620264.

67. Adeli H, Khorasani M, Parvazinia M. Wound dressing based on electrospun PVA/chitosan/starch nanofibrous mats: fabrication, antibacterial and cytocompatibility evaluation and in vitro healing assay. Int J Biol Macromol. 2019;122:238-54.

68. Shen M, Ma N, Li M, Liu Y, Chen T, Wei F, Liu D, Hou W, Xiong $\mathrm{H}$, Yang Z. Antiviral properties of $R$. tanguticum nanoparticles on herpes simplex virus type I in vitro and in vivo. Front Pharmacol. 2019; 10:959.

69. Song J, Lee K, Seong B. Antiviral effect of catechins in green tea on influenza virus. Antivir Res. 2005;68:66.

70. Obata K, Kojima T, Masaki T, Okabayashi T, Yokota S, Hirakawa S, Nomura K, Takasawa A, Murata M, Tanaka S. Curcumin prevents replication of respiratory syncytial virus and the epithelial responses to it in human nasal epithelial cells. PLoS One. 2013;8:70225.

71. Peddinti B, Scholle F, Ghiladi R, Spontak R. Photodynamic polymers as comprehensive anti-infective materials: staying ahead of a growing global threat. ACS Appl Mater Interfaces. 2018; $10: 25955$.

72. Henke P, Kirakci K, Kubát P, Fraiberk M, Forstová J, Mosinger J. Antibacterial, antiviral, and oxygen-sensing nanoparticles prepared from electrospun materials. ACS Appl Mater Interfaces. 2016;8:25127.

73. Si Y, Zhang Z, Wu W, Fu Q, Huang K, Nitin N, Ding B, Sun G. Daylight-driven rechargeable antibacterial and antiviral nanofibrous membranes for bioprotective applications. Sci Adv. 2018; 4 :5931. 